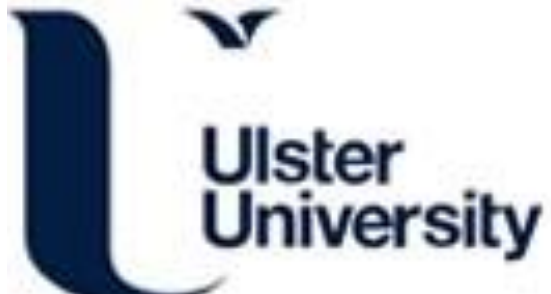

\section{Exploring a Training IRAP as a single participant context for analyzing reversed derived relations and persistent rule-following}

Harte, C., Barnes-holmes, D., Moreira, M., Almeida, J. H., Passarelli, D., \& Rose, J. C. (2021). Exploring a Training IRAP as a single participant context for analyzing reversed derived relations and persistent rulefollowing. Journal of the Experimental Analysis of Behavior, 115(2), 460-480. https://doi.org/10.1002/jeab.671

Link to publication record in Ulster University Research Portal

\section{Published in:}

Journal of the Experimental Analysis of Behavior

Publication Status:

Published (in print/issue): 31/03/2021

DOI:

10.1002/jeab.671

Document Version

Author Accepted version

\section{General rights}

Copyright for the publications made accessible via Ulster University's Research Portal is retained by the author(s) and / or other copyright owners and it is a condition of accessing these publications that users recognise and abide by the legal requirements associated with these rights.

\section{Take down policy}

The Research Portal is Ulster University's institutional repository that provides access to Ulster's research outputs. Every effort has been made to ensure that content in the Research Portal does not infringe any person's rights, or applicable UK laws. If you discover content in the Research Portal that you believe breaches copyright or violates any law, please contact pure-support@ulster.ac.uk. 


\section{Exploring a Training IRAP as a single participant context for analyzing reversed derived relations and persistent rule-following}

Colin Harte ${ }^{1}$, Dermot Barnes-Holmes ${ }^{2}$, Murilo Moreira ${ }^{3}$, Joao H. de Almeida ${ }^{4}$, Denise Passarelli ${ }^{3} \&$ Julio C. de Rose ${ }^{3}$

${ }^{1}$ Department of Psychology, National College of Ireland, Dublin, Ireland ${ }^{2}$ School of Psychology, Ulster University, Coleraine, Northern Ireland, UK ${ }^{3}$ Department of Psychology, Federal University of Sao Carlos, Sao Carlos, Sao Paulo, Brazil ${ }^{4}$ Department of Psychology, Londrina State University, Londrina, Parana, Brazil

Authors' Note: Data collection was supported by the National Institute of Science and Technology on Behavior, Cognition, and Learning, with funds from the São Paulo Research Foundation (FAPESP, Grant \#2014/50909-8) and the Brazilian Council for Scientific and Technological development (CNPq, Grant \#465686/2014-1). The third author was supported by a Master Scholarship from the Brazilian Coordination for the Improvement of Higher Education Personnel (CAPES; Finance Code 001), and the fifth author was supported by a Master Scholarship from FAPESP (Grant \#2019/01406-7).Correspondence concerning this article should be sent to colin.n.harte@gmail.com 


\begin{abstract}
Rule-governed behavior and derived stimulus relations have always shared strong conceptual links within behavior analysis. However, experimental analysis linking the two domains remains limited. The current study consisted of three experiments that aimed to continue to bridge this experimental gap. The first experiment sought to establish the extent to which a training version of the implicit relational assessment procedure (IRAP) could be used to establish and successfully reverse experimentally-established derived relations. The results suggested that the Training IRAP could successfully produce derived reversals. Experiments 2 and 3 explored the extent to which reversed derived relations would control rule-governed behavior when the contingencies for rule-following competed with the rule. In Experiment 2, the task contingencies were immediately in opposition to the (reversed) derived rule, and participants generally responded in accordance with the task contingencies, rather than the rule. In Experiment 3, the task contingencies were initially rule-consistent before a contingency reversal that later made them rule-inconsistent. Here evidence of rule-persistence emerged. The results of the research are considered within the context of a recent framework that has emerged out of RFT for analyzing the dynamics involved in derived relational responding.
\end{abstract}

KEY WORDS: RULE-FOLLOWING; DERIVED RELATIONS; FLEXIBILITY;

COHERENCE; SINGLE PARTICIPANT DESIGN; HDML 
Two well-established and widely used concepts in behavior analysis are closely associated with the analysis of human language and cognition. The first of these, rule-governed behavior, was proposed by Skinner (1966). Specifically, it was argued that rules controlled behavior in part because they specified reinforcement contingencies, which could override the effects of direct contact with those contingencies. For example, if a participant was told that the best way to earn points on a fixed-interval (FI) schedule was to keep pressing as quickly as possible, the rule or instruction could generate relatively high levels of responding even though reinforcers were available for responding at a very low rate (e.g., Weiner, 1964, 1969). While recognizing the clear utility of the concept of rules and rule-governed behavior, and the experimental support for that concept, it has also been recognized that there is a certain lack of technical precision in the concept itself (Harte, et al., 2020a). For example, the claim that rules or instructions specify contingencies seemingly requires a functional-analytic account of specification itself.

Such an account emerged from a second well-established concept in the behavior analysis of human language and cognition, that of equivalence and other derived stimulus relations. This concept originated in Sidman's (1971) finding that reinforcing a number of related matching responses frequently produced a number of emergent or unreinforced matching responses in human participants (e.g., if the stimulus relations A-B and A-C were trained, emergent or derived B-C and C-B relations were observed). Critically, Sidman (1994) argued that words or symbols may specify contingencies by participating in equivalence relations with the events to which they refer. Imagine, for example, that the rule "when the light goes green, press the button for points" controlled appropriate button pressing. The actual behavior of button pressing in the presence of green would occur not simply through direct contact with the reinforcement contingency, but because the words in the rule were in 
equivalence relations with the actual objects and actions specified by the rule (e.g., the word 'green' would be in an equivalence relation with the actual green stimulus).

Clearly, the concepts of rule-governed behavior and equivalence/derived relations were linked conceptually from relatively early on (see also Hayes \& Hayes, 1989), but experimental analyses linking the two domains have remained limited. Until recently, only a small number of studies had tested a derived relations model of specification (e.g., O'Hora et al., 2004; O'Hora et al., 2014). None of these studies, however, had explored the extent to which specification within a rule, involving a derived relation, would override a direct reinforcement contingency. The first study that provided clear evidence for such an effect established a derived equivalence relation between the phrase "least like" and a nonsense word "beda" (Harte et al., 2017). The nonsense word was then inserted into a rule that instructed participants to choose a comparison stimulus in a matching-to-sample (MTS) task that was the least like the sample stimulus. Following the rule was initially reinforced but the contingencies subsequently reversed and thus the rule now specified a direct contingency that no longer applied. This study and others that followed provided evidence that rules involving derived relations could override the impact of contact with direct contingencies (Bern et al., 2020; Harte et al., 2018; Harte et al, 2020b).

In exploring the extent to which rules involving derived relations may override direct contingencies, an analysis of the derived relations per se seems to be required. One important feature of derived relational responding is the extent to which derived relations are reversible when the baseline contingencies for establishing those relations are reversed. It has been argued that addressing this issue is important because it may reveal the extent to which derived relations are under the control of the most recently reinforced baseline relations or the initially reinforced relations. In broader terms, the key issue pertains to how readily derived relational responding may be changed or influenced in the experimental laboratory and the 
potential implications this may have for attempting to change relational responding in applied contexts. This question was explored extensively in seminal research conducted by Pilgrim and Galizio (1990, 1995; see also Pilgrim et al., 1995). These authors first trained two sets of $\mathrm{AB}$ and $\mathrm{AC}$ relations (i.e., $\mathrm{A} 1-\mathrm{B} 1, \mathrm{~A} 1-\mathrm{C} 1$, and $\mathrm{A} 2-\mathrm{B} 2, \mathrm{~A} 2-\mathrm{C} 2$ ) and documented the formation of two three-member derived equivalence classes (i.e., A1-B1-C1 and A2-B2-C2).

Subsequently, some of the trained baseline relations were reversed (A1-C2 and A2-C1).

Although symmetry performances were successfully controlled by the baseline reversals (i.e., C2-A1 and C1-A2), transitivity performances remained consistent with the original performances (i.e., B1-C1 and B2-C2 rather than B1-C2 and B2-C1). Subsequent research has explored some of the variables that may be involved in determining whether or not full reversals are obtained in both symmetry and transitive relations following baseline reversal (e.g., Garotti et al., 2000; Garotti \& de Rose, 2007; de Almeida \& de Rose, 2015; see also recent research on relational density theory, which aims to develop quantitative models of the variables that predict the relative strength in derived relational responding; e.g., Belisle \& Dixon, 2020a, 2020b).

To date, no research has explored the extent to which a rule that contains a derived relation, which has been reversed, would override a competing reinforcement contingency. The experiments reported in the current study aimed to address this question. In conducting this work, we adopted a methodology (a training version of the implicit relational assessment procedure $[\text { IRAP }]^{1}$ ), similar to that employed by Harte and colleagues (e.g., 2018, and Harte

\footnotetext{
${ }^{1}$ A reviewer queried the descriptor "IRAP" because the 'implicit' component of the paradigm (i.e., rapid switching between blocks of history-consistent and history-inconsistent trials to calculate a difference score) was not used in the current research. The descriptor 'Training-IRAP' is used because it is part of the existing software package, available for free download, and is formally labelled the GO-IRAP. Furthermore, the 'Training IRAP' label itself has already been documented in the literature in a manner consistent with the current research (e.g., Harte et al., 2018, 2020b) and also in other research domains (e.g., Leech \& Barnes-Holmes, 2020). At this point it would likely cause unnecessary confusion in the research community if we now deviated from the 'Training-IRAP' label.
} 
et al., 2020b) for training and testing, and then reversing and retesting the relevant derived relations. We opted to use this methodology because this recent work had successfully demonstrated that derived rules could indeed override direct reinforcement contingencies, at least for a limited number of trials. Reversal of derived rules, however, has not yet been investigated in this research. Furthermore, while the previous studies by Harte et al. explored derived rule following at the group level, the current study employed a single-participant design to demonstrate high levels of behavioral prediction and influence.

The study consisted of three experiments, the first of which simply sought to establish the extent to which a Training IRAP could be used to establish and successfully reverse both symmetry and transitive relations. Specifically, participants were trained to respond to pairs of stimuli using response options that confirmed or disconfirmed the relations (e.g., A1-B1 confirm with "True"; A1-B2 disconfirm with "False"). This type of training was used to establish a relational network consisting of two three-member equivalence classes (i.e., $\mathrm{A} 1=\mathrm{B} 1=\mathrm{C} 1$ and $\mathrm{A} 2=\mathrm{B} 2=\mathrm{C} 2)$. Subsequently, the $\mathrm{B}$ and $\mathrm{C}$ relations were reversed, and the new class structure was tested (i.e., $\mathrm{A} 1=\mathrm{B} 1=\mathrm{C} 2$ and $\mathrm{A} 2=\mathrm{B} 2=\mathrm{C} 1$ ). The experiment involved multiple reversals to determine the extent to which reversing contingencies using the IRAP in this way would demonstrate relatively flexible responding in the formation of a derived relational network. Experiments 2 and 3 then explored the extent to which inserting derived relations from networks in which the derived relations had been reversed would control rulegoverned behavior when the contingencies for rule-following competed with the rule. The details of these two latter experiments will be outlined following the description of Experiment 1.

Before continuing, it seems important to note that the research reported here was guided in part by a new framework (mentioned above) for analyzing the dynamics involved in derived relational responding; the Hyper-Dimensional Multi-Level (HDML) framework 
(Barnes-Holmes et al., 2020; Barnes-Holmes, et al., 2017). In brief, the HDML divides derived relational responding into five levels of relational development that have emerged from conceptual and empirical analyses within Relational Frame Theory (RFT; Hayes, et al., 2001); a behavior-analytic account of human language and cognition. These levels are: mutual entailment (e.g., symmetry in equivalence research), combinatorial entailment (e.g., transitivity in equivalence research), relational networks, relating relations, and relating relational networks. In the HDML framework, each of these levels intersects with four dimensions; coherence, complexity, derivation and flexibility. The two dimensions that are most relevant to the current research are flexibility and coherence because they appear to connect most directly to changing or influencing behavior in relation to a previous history of reinforcement for that behavior itself (e.g., does flexibility increase with decreased coherence between current and past reinforcement histories?). Flexibility was deemed critical within the current research because reversing a subset of the baseline relations led to clear reversals in the derived combinatorially entailed relations; within the HDML framework, such reversals have been suggested as evidence for relational flexibility. Coherence was deemed important within the current research because it refers to the extent to which a relational network, such as a rule, is consistent with (coheres with) other relational networks. In general, all things being equal, a relational network that is relatively high in coherence will possess greater behavior-controlling properties than a relational network that is relatively low in coherence. Later in the current article, we will argue that persistent rule-following in the face of competing reinforcement contingencies may be usefully interpreted as evaluating the various properties (in this case coherence) of two relational networks; specifically, the derived rule provided within the experiment versus the rule generated by direct exposure to the task contingencies. Finally, it is again worth noting that unlike previous research in this area (i.e., Bern et al., 2020; Harte et al., 2017, 2018; 2020b), the current study employed single-case 
experimental designs in order to demonstrate high levels of behavioral prediction and influence.

\section{Experiment 1}

\section{Method}

\section{Participants}

Four individuals participated in Experiment 1; two females and two males. They ranged in age from 19 to 27 years and were recruited through convenience sampling from the Federal University of São Carlos (UFSCar). All participants were native Portuguese speakers. The data from one participant were excluded because they had to leave the experiment early due to a prior commitment, leaving $N=3$ for analysis. Participants were offered coffee and biscuits upon arrival, but did not receive any other compensation for participation.

\section{Setting}

Participants were seated in front of a standard laptop in an experimental cubicle at UFSCar. The experimenter was present while participants completed a Derivation PreTraining task and during training of baseline relations. Participants were alone while completing testing of derived relations (see below).

\section{Materials and Apparatus}

The experiment involved two computer-based tasks: a Derivation Pre-Training task and a Training IRAP.

The Derivation Pre-training Task. An adapted version of the Derivation PreTraining Task employed by Harte and colleagues (2020b) was employed. Harte et al. noted that pre-training appeared to reduce attrition in the context of persistent rule-following, and thus, it was employed in the current series of experiments (although Experiment 1 did not examine persistent rule-following, the pre-training was employed to maintain procedural integrity across subsequent experiments). Specifically, the purpose of the Derivation Pre- 
training Task was to provide participants with a history within the experiment of relating stimuli that were deemed to be semantically similar or different. In total, the task involved six sets of stimuli, with each set containing three stimuli (see Table 1). The overarching purpose of this task was to prepare participants for deriving target relations with completely novel stimuli at a later stage in the experiment.

\section{INSERT TABLE 1 HERE}

The Derivation Pre-training Task was presented in Microsoft PowerPoint. All trials presented a label stimulus at the top of the screen (e.g., "Livro", the Portuguese word for "Book"), a target stimulus in the centre (the Spanish word for book, "Libro"), and two response options, for example, the Portuguese words "Correto" (meaning correct) and "Incorreto" (meaning incorrect), which appeared at the bottom left and right of the screen ("True" versus "False", "Yes" versus "No", or "Right" versus "Wrong" were also employed as response options on some trials).

The Training IRAPs. The IRAPs employed stimuli from Sets 7 and 8 (see Table 2). Portuguese words and phrases were presented during all phases but the English translations are used here. During training of the A-B relations, each trial presented a label at the top of the screen, a single target in the centre of the screen, and two response options. The label stimulus was one of two phrases "Least Similar" (A1) or "Most Similar" (A2; the Portuguese translations for Least Similar and Most similar, Menos Parecido and Mais Parecido respectively were employed in the experiment), the target stimulus was "TTT" (B1) or "]][[" (B2), and each pair of response options comprised "True" versus "False", "Yes" versus "No", “Correct" versus "Incorrect", or "Right” versus "Wrong”(see Figure 1).

INSERT TABLE 2 \& FIGURE 1 HERE 
During training of the B-C relations, each trial presented the stimuli "TTT" (B1) or "]][[" (B2) as labels, the novel words "Beda" (C1) and "Sarua" (C2) as targets, along with the same response options (see Figure 2).

\section{INSERT FIGURE 2 HERE}

The mixed A-B/B-C Training IRAP was similar to the A-B and B-C Training IRAPs, except that A-B and B-C relations were presented within each block of training trials, rather than across two separate IRAPs. The final Training IRAP presented the untrained A-C relations that could be derived from the mixed A-B and B-C Training IRAPs. Specifically, each trial presented the stimulus "Least Similar" (A1) or "Most Similar" (A2) as labels, with the novel words "Beda" (C1) or "Sarua" (C2) as targets, along with the same response options as before (see Figure 3).

\section{INSERT FIGURE 3 HERE}

\section{Procedure}

The Derivation Pre-training Task. As noted previously, the aim of the Derivation Pre-training Task was to provide participants with the opportunity to derive relations of sameness and difference between two stimuli based on a single "mediating" third stimulus. 42 trials were presented in total. On each trial, the two stimuli on the screen were read aloud by the Experimenter (e.g., Livro with Libro). Participants were asked to confirm or deny whether these two stimuli had the same meaning using the response options (e.g., yes or no). Corrective feedback was provided by the experimenter for each response before immediately presenting the next trial. The task consisted of three separate training cycles, each containing the same three phases (see Table 3; only the stimuli involved in each cycle and phase differed; see Table 1 above). Within each phase, the stimuli were presented in pairs such that for some pairs participants would likely know the relation between them (because they were Portuguese and Spanish words and involved considerable semantic overlap). For other pairs, 
the relation between them would be unknown because the pairs contained an Irish word (e.g., "Madra" and "Leabhar") or a nonsense stimulus (i.e., "XXX" or "////"), and would thus have to be trained. The remaining pairs contained words that allowed participants to derive a relation between a known Portuguese word and a previously unknown Irish word. Participants progressed immediately from one phase to the next and from one cycle to the next. Upon completion of the final phase within the final cycle, participants progressed immediately onto the Training IRAP.

\section{INSERT TABLE 3 HERE}

The Training IRAPs. The Training IRAPs were presented within two separate sequences: a baseline sequence and a reversal sequence (see Figure 4). Each sequence contained three Training IRAPs designed to establish novel relations (e.g., A1=B1, A2=B2, $\mathrm{B} 1=\mathrm{C} 1$, and $\mathrm{B} 2=\mathrm{C} 2$ ), and a fourth Training IRAP designed to test a derived relational response involving these relations (e.g., $\mathrm{A} 1=\mathrm{C} 1$ and $\mathrm{A} 2=\mathrm{C} 2)^{2}$. While the stimuli involved in each Training IRAP sequence remained identical, the B and $\mathrm{C}$ stimuli were reversed in one sequence relative to the other. That is, in the baseline training sequence, participants were trained that $\mathrm{B} 1=\mathrm{C} 1$ and $\mathrm{B} 2=\mathrm{C} 2$. However, in the following reversed training sequence, participants were trained that $\mathrm{B} 1=\mathrm{C} 2$ and $\mathrm{B} 2=\mathrm{C} 1$. Therefore, the correct derived $\mathrm{A}=\mathrm{C}$ responses would be reversed across training sequences (see Experiment 1 in Figure 4).

\section{INSERT FIGURE 4 HERE}

Before commencing the Training IRAP, participants were provided with instructions on how to complete this task. Specifically, they were advised that each trial would present a phrase at the top of the screen alongside a symbol in the centre, and that their task was to

\footnotetext{
${ }^{2}$ The reader should note that we use the term 'Training IRAP' to describe a sequence of IRAPs, the last of which functions as a test of the derived relations. The term 'Training' is employed here because the term test IRAP is typically reserved for the complete IRAP procedure in which participants are required to reverse their responses across blocks of IRAP trials and differences in latency/accuracy across blocks are used as a measure of response strength. In the current study, no such 'test' IRAP was used and thus all IRAPs refer to Training IRAPs.
} 
accurately relate these together using one of the two response options provided across each block (i.e., pressing $D$ for the option on the left or $K$ for the option on the right). Participants were then invited to begin the task which then worked through the sequence illustrated in Figure 4. The final Training IRAP was referred to as a test IRAP because no programmed differential response feedback was presented. Participants alternated between each Training IRAP sequence until three iterations of each sequence had been completed.

A-B Relations Training IRAP. The A-B relations Training IRAP consisted of a block of 24 trials involving "Least Similar" (A1) and "TTT" (B1) from Set 7, and "Most Similar" (A2) and "]][[" (B2) from Set 8. There were four trial types involved in this phase: Least Similar-TTT; Least Similar-]][[; Most Similar-]][[; and Most Similar-TTT. Correct responding was as follows: Least Similar-TTT/True; Most Similar-TTT/False; Least Similar]][[/False; and Most Similar-]][[/True. There were six exposures to each trial type, presented quasi-randomly within each block of 24 trials. If a correct response was emitted the word "Right!" appeared immediately in the centre of the screen, and the next trial appeared 400ms later. If an incorrect response was emitted, a red X appeared until a correct response was emitted. Participants received automated feedback on their overall accuracy and latency performances at the end of the first block of trials. If participants failed to achieve a mean accuracy $(\geq 80 \%)$ and/or a mean latency $(\leq 3000 \mathrm{~ms})$ per trial type during this block, they were re-exposed to another block of the same until these criteria were reached, at which point they could proceed to the B-C relations Training IRAP.

B-C Relations Training IRAP. The B-C relations Training IRAP consisted of a block of 24 trials involving "TTT" (B1) and "Beda" (C1), and "]][[” (B2) and "Sarua" (C2). The four trial-types were: TTT-Beda; TTT-Sarua; ]][[-Sarua; and ]][[-Beda. During the baseline sequence, correct responding was as follows: TTT-Beda/True; ]][[-Beda/False; TTTSarua/False; and ]][[-Sarua/True. During the reversed sequence however, correct responding 
was as follows: TTT-Beda/False; ]][[-Beda/True; TTT-Sarua/True; and ]][[-Sarua/False. Again, there were six exposures to each trial type and all other aspects were identical to the A-B relations Training IRAP.

Mixed A-B and B-C Relations Training IRAP. The mixed A-B and B-C relations Training IRAP consisted of a block of 32 trials involving all of the stimuli from Sets 7 and 8 . The label and target stimuli were presented in the same manner in which they had been presented in the A-B and B-C Training IRAPs above, but all within the same block. Each of the four trial types from both A-B and B-C Training IRAPs were presented four times each quasi-randomly. All other aspects were identical to the A-B and B-C relations Training IRAPs. It is important to emphasize that all participants received feedback on each trial throughout each Training IRAP thus far.

Derived A-C Relations Test IRAP. The A-C relations test IRAP presented participants with a single block of previously untrained A-C relations. At the beginning of this block, participants were advised that they would see some of the stimuli that they had seen before but presented in combinations that they had not seen before. Participants were also explicitly instructed not to worry about speed of responding (because the target relations were novel) but to focus on accuracy. They were informed that they would no longer receive feedback at any point, but that it was still possible to get all trials correct. Within this phase, the labeltarget combinations gave rise to the following four trial-types: Least Similar-Beda; Least Similar-Sarua; Most Similar-Sarua; and Most Similar-Beda. During the baseline training sequence, correct responding was as follows: Least Similar-Beda/True; Most SimilarBeda/False; Least Similar-Sarua/False; and Most Similar-Sarua/True. During the reversed training sequence however, correct responding was: Least Similar-Beda/False; Most SimilarBeda/True; Least Similar-Sarua/True; and Most Similar-Sarua/False. No performance criteria were applied in this Training IRAP. Thus, all participants proceeded through this block and 
then immediately back to the A-B relations Training IRAP in either the baseline or reversed relation sequence, depending on what sequence they had just completed. After completing six sequences in total (i.e., three baseline sequences alternating with three reversal sequences) participants were debriefed and thanked for their participation.

\section{Results and Discussion}

\section{IRAP Data}

Training Blocks. The number of blocks required by participants to reach the performance criteria on each Training IRAP are listed in Table 4 (for a more detailed breakdown of participants' performances per trial-type refer to Appendix A). All participants required, with one exception on one block (see Participant 2), 1-2 blocks of training trials to reach criteria on each of the three A-B, B-C, and mixed A-B and $\mathrm{B}-\mathrm{C}$ relations training across baseline and reversal sequences. On their final block of training, all participants produced $\geq$ $83 \%$ correct ( 5 of 6 ) on the A-B and B-C relations training, and $\geq 87.5 \%$ correct ( 7 of 8 ) on the mixed A-B and B-C relations training.

A-C Test Blocks. The main aim of Experiment 1 was to determine if A-C relations were derived in accordance with the most recently trained A-B and B-C relations. Participants' A-C performances per trial type (\% accuracy) are presented in Figure 5. In all cases, the derived A-C performances appeared to be sensitive to the A-B/B-C training. Indeed, with the exception of the first reversal training for Participant 1 , the derived A-C performances shifted almost entirely in accordance with the preceding reversal training. And even in the case of Participant 1, the derived A-C relations test was clearly impacted upon by the reversal training. That is, in no case, did any of the three participants simply persist with their previous A-C test performances.

\section{Insert Figure 5 here}


At this point, it was clear that the procedure adopted in the current experiment could successfully control the derived A-C relations in accordance with the most recently trained A$\mathrm{B}$ and $\mathrm{B}-\mathrm{C}$ relations, thus demonstrating the required level of relational flexibility to conduct the subsequent experiments. Experiments 2 and 3 addressed the extent to which those reversals impacted upon a separate testing context that was designed to examine a phenomenon referred to as persistent rule-following.

\section{Experiment 2}

As mentioned in the introduction, until relatively recently, the study of derived relational responding had been conducted more or less in isolation from the study of rulegoverned behavior. On balance, the two areas had been linked conceptually by the main progenitors of research on derived relations (see Sidman, 1994), and RFT more generally (Hayes \& Hayes, 1989; see also Harte et al., 2020a, for a detailed review of this area). Recent attempts to bridge the gap between these two research areas have involved training and testing a simple relational network and inserting a derived element of that network into a rule for responding on a contingency switching MTS task. The critical measures involved determining the extent to which participants would persist with the derived rule when the contingencies switched and were thus inconsistent with that rule (e.g., Harte et al., 2017, 2018; 2020b). Experiments 2 and 3 reported here employed the derived (persistent) rule-following paradigm developed by Harte et al. to determine if flexibility in reversing the derived A-C relations in Experiment 1 would generalize in a persistent rule-following context. Specifically, in Experiment 2, participants were trained and tested in a relational network identical to that in Experiment 1. Immediately thereafter, they were exposed to an MTS task which required responding in accordance with the derived rule. Participants were then trained and tested in a relational network that involved reversing the trained $\mathrm{B}-\mathrm{C}$ and tested $\mathrm{A}-\mathrm{C}$ relations. They were then re-exposed to the MTS task, which now provided contingency feedback that was 
inconsistent with the reversed derived A-C based rule. Assuming that participants flexibly reversed the derived A-C relations, would this reversal impact upon performance on the MTS task in the face of competing task contingencies? In other words, would the reversed derived rule control responding when it contradicted the MTS contingencies?

\section{Participants}

Four individuals participated in Experiment 2, two females and two males. They ranged in age from 19 to 31 years and were recruited through random convenience sampling at UFSCar. All participants were native Portuguese speakers. The data from one participant were excluded because they failed to meet performance criteria on the A-B relation Training IRAP, leaving $N=3$ for analysis. Participants were offered coffee and biscuits upon arrival, but did not receive any other compensation for participation.

\section{Setting}

The setting was identical to Experiment 1.

\section{Materials and Apparatus}

The experiment involved the same Derivation Pre-Training task and Training IRAPs employed in Experiment 1. In Experiment 2, all participants were also required to complete an MTS procedure following each A-C test IRAP sequence (see Figure 6). All other aspects were identical to Experiment 1.

The MTS task involved six blocks comprised of 15 trials each. On each trial, a sample stimulus was presented at the top of the screen, while three comparison stimuli were presented along the bottom of the screen. Each stimulus was a random shape, none of which was identical to another, and all of which varied in similarity to the sample stimulus. That is, one comparison was very clearly the most similar comparison to the sample (see centre Figure 6), one was clearly quite similar to the sample but contained more variations in form (see left hand-side of Figure 6), and one was clearly the least similar comparison to the sample (see 
right hand-side of Figure 6). Each sample/three comparison combination made up a single individual stimulus set. Within each stimulus set, only those three comparison stimuli appeared in the presence of that sample stimulus. A total of 56 stimulus sets were employed, with each set presented at least once, and no more than twice across the six MTS blocks. Participants responded by choosing the key that corresponded with the position of each comparison stimulus (D, G, or K, on a qwerty keyboard).

\section{INSERT FIGURE 6 HERE}

\section{Procedure}

Participants first completed the same Derivation Pre-Training task and Training IRAPs as in Experiment 1. As in Experiment 1, the Training IRAPs alternated between three baseline training sequences and three reversed training sequences. In Experiment 2, however, each IRAP sequence was immediately followed by a block of 15 MTS trials. At the beginning of the MTS task, participants were provided with relevant instructions. In summary, they were first told that each trial would present a shape at the top of the screen along with three shapes along the bottom. They were asked to choose the image that was "Beda" to the image at the top of the screen. Participants were told that they would receive one point for each correct response and that they would lose one point for each incorrect response. Finally, participants were informed that the cumulative score within each block of MTS trials would appear after each trial. It is important to note that the instructions remained identical for each MTS block, regardless of the IRAP sequence that preceded it. Thus, following the baseline relation sequence, the 'BEDA' instruction was functionally equivalent to "choose the least similar comparison", but following the A-C reversal sequence, the 'BEDA' instruction was functionally equivalent to "choose the most similar comparison." Crucially, the MTS contingencies remained the same throughout the experiment. Thus, participants were always awarded one point for choosing the least similar image and deducted one point for choosing 
the most similar image. For the MTS blocks that followed the baseline relation sequence, therefore, responding in accordance with the initial instruction would always result in a point being awarded. Following the reversal relations sequence, however, responding in accordance with the instruction would always result in a point being deducted.

\section{Results and Discussion}

\section{IRAP Data}

Training Blocks. The number of blocks required by participants to reach the performance criteria on each Training IRAP are listed in Table 4 (once again, for a more detailed break-down of participant performance per trial-type per training, see Appendix A). Similar to Experiment 1, all participants required, with one exception on one block (see Participant 3), 1-2 blocks of training trials to reach criteria on each of the three A-B, B-C, and mixed A-B and B-C relations training blocks, across baseline and reversal sequences. Once again, on their final block of training, all participants produced $\geq 83 \%$ correct ( 5 of 6 ) per trial-type on the A-B and B-C relations training, and $\geq 87.5 \%$ correct ( 7 of 8 ) per trial type on the mixed A-B and B-C relations training.

A-C Test Blocks. As was the case in Experiment 1, it was important to first determine if the A-C relations were successfully derived in accordance with the most recently trained AB and B-C relations. Participants' A-C performances per trial type ( $\%$ accuracy) are presented in Figure 7 (top graphs). In all cases, the derived A-C performances appeared to be sensitive to the A-B/B-C training. That is, for all three participants, the derived A-C performances shifted almost entirely in accordance with the preceding reversal training. Thus, it was once again evident that IRAP training successfully controlled the derived A-C relations in accordance with the most recently trained A-B and B-C relations.

\section{INSERT FIGURE 7 HERE}

\section{MTS}


The primary aim of Experiment 2 was to determine the extent to which the derived AC reversals impacted upon participants' performance on the MTS tasks as a context for persistent rule-following. As explained previously, in all MTS blocks that followed A-C baseline test blocks, the task contingencies were consistent with the derived rule for responding; however, in all MTS blocks that followed the A-C reversal test, the task contingencies were in opposition to the derived rule (see bottom graphs Figure 7). In the case of the former, all participants demonstrated an almost perfect MTS performance (i.e., followed the derived rule and received points for doing so). In the case of the latter, however, participants appeared to initially follow the derived rule, but only for between one and four trials. Thus there was little evidence for persistent rule-following when the rule was no longer consistent with the task contingencies.

\section{Experiment 3}

The results of Experiment 2 suggested that the derived rule had minimal impact on an MTS performance when the 'meaning' of the derived rule was reversed, but the original MTS contingencies were maintained. One important difference between the current study and the previous research reported by Harte et al. $(2017,2018,2020 b)$ is that in these earlier studies, the MTS contingencies were reversed during exposure to the task but in the current study the contingencies remained unchanged (i.e., it was the derived rule that was reversed).

Experiment 3 was a partial replication of Experiment 2, but the MTS procedure involved a reversal in the task contingencies. Specifically, following the reversed A-C training sequence, the first 15 trials of the MTS were also reversed (i.e., consistent with the reversed rule), but for the final 15 trials, the MTS task reverted back to baseline consistent contingencies. The purpose of Experiment 3 was to determine if contacting MTS contingencies that were consistent with the reversed rule would produce greater evidence of persistent rule-following relative to Experiment 2. 


\section{Method}

\section{Participants}

Five individuals participated in Experiment 1, three females and two males. They ranged in age from 19 to 24 years and were recruited through random convenience sampling from the online participant system at UFSCar. All participants were native Portuguese speakers. The data from 2 participants were excluded (one failed to meet the required performance criteria on the first mixed A-B and B-C relations Training IRAP, while the other required 9 blocks of training to reach criteria on the first A-B training block and as a result had not enough time to complete the entire experiment), leaving $N=3$ for analysis. While participants were offered coffee and biscuits upon arrival, they did not receive any other compensation for participation.

\section{Setting}

The setting was identical to Experiments 1 and 2.

\section{Apparatus and Materials}

The same Derivation Pre-Training Task and Training IRAPs employed in Experiments 1 and 2 were again employed in Experiment 3. The MTS task employed in Experiment 3 was similar to Experiment 2 except that now each MTS block contained 30 trials instead of 15 . Additionally, a total of 67 stimulus sets were employed, with each set presented at least once, and no more than three times in the four MTS blocks.

\section{Procedure}

Participants first completed the same Derivation Pre-Training task and Training IRAPs as in Experiment 1. Each IRAP sequence was followed by a block of MTS trials (as in Experiment 2), but now these blocks comprised 30 trials instead of 15 . For the 30 trials that followed the baseline A-C test, task contingencies were rule-consistent throughout the block (i.e., for all 30 trials). For the 30 trials that followed the A-C reversal test, the task contingencies for the first 15 trials were rule-consistent, but for the remaining 15 trials the 
contingencies switched without warning and were thus rule-inconsistent. The reader should note, that in Experiment 2 participants completed both baseline and reversal sequences 3 times each, but in the current experiment this was reduced to two reversals so that the duration of the two experiments was broadly similar. The main purpose of the experiment was to determine if contacting MTS contingencies that were consistent with the reversed derived rule would impact upon persistent rule-following when the MTS contingencies were reversed (and thus the rule was no longer MTS consistent).

\section{Results and Discussion}

\section{IRAP Data}

Training Blocks. The number of blocks required by participants to reach the performance criteria on each Training IRAP are listed in Table 4 (for a more detailed breakdown of participant performance per trial type per training, see Appendix A). Similar to Experiments 1 and 2, all participants required, with one exception on one block (see Participant 2), 1-2 blocks of training trials to reach criteria on each of the three A-B, B-C, and mixed $\mathrm{A}-\mathrm{B}$ and $\mathrm{B}-\mathrm{C}$ relations training across baseline and reversal sequences. Once again, on their final block of training, all participants produced $\geq 83 \%$ correct ( 5 of 6 ) on the A-B and $\mathrm{B}-\mathrm{C}$ relations training, and $\geq 87.5 \%$ correct ( 7 of 8 ) on the mixed $\mathrm{A}-\mathrm{B}$ and $\mathrm{B}-\mathrm{C}$ relations training.

A-C Test Blocks. As was the case in both Experiments 1 and 2, it was important to first determine if A-C relations were derived in accordance with the most recently trained A-B and B-C relations. Participants' A-C performances per trial type ( $\%$ accuracy) are presented in Figure 8. Once again, in all cases, the derived A-C performances appeared to be sensitive to the A-B/B-C training. That is, in all three participants the derived A-C performances shifted almost entirely in accordance with the preceding reversal training. Thus, it was once again 
evident that IRAP training successfully controlled the derived A-C relations in accordance with the most recently trained A-B and B-C relations.

\section{Figure 8}

\section{MTS}

With the exception of one response for one participant, the MTS performances following baseline A-C tests were consistent with both the rule and the task contingencies (see Figure 8). Following the A-C reversal test, performances on the first 15 trials of the MTS task were almost entirely consistent with the reversed rule and task contingencies. When the MTS contingencies switched for the final 15 trials (thus rendering the rule inconsistent), there was clear evidence of greater persistence in rule-following relative to Experiment 2. This was particularly pronounced for Participant 3 who persisted with derived rule-following across all trials following both exposures to the MTS contingency switch. The same pattern was observed for Participant 2 during their second exposure to the MTS contingency switch, with some evidence of persistent rule-following during the first exposure (i.e., the first six responses after the switch remained rule-consistent). A broadly similar, albeit more variable, pattern was observed for Participant 1 during the first exposure to the MTS contingency switch (i.e., a total of eight rule consistent responses), but virtually no rule-persistence was observed during the second exposure. Overall therefore, it appears that exposure to a contingency switch within a block of MTS trials facilitated greater derived rule-persistence than when the contingency switch occurred across blocks of MTS trials.

\section{General Discussion}

The aims of the current series of experiments were twofold. First, could the IRAP be used as a training and testing context for flexibly reversing combinatorially entailed (A-C) relations, given that earlier studies using the MTS paradigm had indicated that such reversals do not always readily occur (e.g., Pilgrim \& Galizio, 1995, 1990; but see Smeets et al., 2003)? 
Second, assuming that such reversals would be readily observed with the IRAP, to what extent would reversed derived relations, when inserted into a rule, impact upon persistent rule-following? In the case of the first aim, the results of Experiment 1, and indeed Experiments 2 and 3, suggested that the Training IRAP could successfully produce flexibility in derived A-C reversals. That is, all nine participants across the three experiments showed clear evidence of reversing a previously derived A-C relation.

The extent to which derived A-C relations impacted upon rule persistence in the face of competing MTS contingencies was less clear cut. Specifically, in Experiment 2, when the task contingencies were in opposition to the (reversed) derived rule, participants generally responded in accordance with the MTS contingencies, rather than the rule. However, in Experiment 3 when MTS contingencies were reversed initially during a block of 30 trials, and were thus rule-consistent, evidence of rule-persistence emerged when the MTS contingencies switched again and thus became rule-inconsistent. In the context of the current experiment, therefore, persistent rule-following only emerged when participants had contacted a reversal in the MTS contingencies.

The current research clearly raises a number of questions. The first of these pertains to why the IRAP training and testing format was so successful in producing reversals in the derived A-C relations? Although the answer must remain speculative, perhaps one likely explanation is that the IRAP directly establishes both relations of coordination and distinction. That is, participants are required to confirm each of the coordinated relations (e.g., A1-B1True; A2-B2-True) and to disconfirm each of the distinct relations (e.g., A1-B2-False; A2-B1False). In contrast, in an MTS context, participants are simply required to choose the correct comparison (e.g., A1 choose B1; A2 choose B2). Of course, in doing so, they are also not choosing the incorrect comparison, but this relational response is not directly targeted in the procedure. Indeed, it has long been argued that two comparisons in MTS may be problematic 
because training and/or test performances may involve choosing the correct, or rejecting the incorrect, comparison (e.g., Carrigan \& Sidman, 1992; Johnson \& Sidman, 1993, Perez et al., 2015, 2017). Notwithstanding the important issues surrounding the argument for more than two comparisons in MTS, it remains the case that the four trial-type structure of the IRAP appears to circumvent this problem (i.e., by requiring both confirming and disconfirming responses; see de Rose et al., 2013, and Arantes \& de Rose, 2015, for broadly similar arguments). Given the increased relational precision afforded by the IRAP relative to MTS, at least when using only two comparisons, it is possible that such precision increases the likelihood that previously derived relations will be flexibly reversed following appropriate reversals in the baseline relations. On balance, it is worth noting that some researchers have reported reliable reversals in derived combinatorially entailed relations using MTS (Garotti, et al., 2000; Garotti \& de Rose, 2007; de Almeida \& de Rose, 2015). A number of variables seem to be involved in producing successful reversals such as using delayed rather than simultaneous MTS (de Almeida \& de Rose 2015), providing participants with a complete baseline review of all training trials before the critical test (Garotti, et al., 2000; Garotti \& de Rose, 2007), and using more than two comparisons (Garotti \& de Rose, 2007). Obviously, a systematic analysis of all of the variables involved in producing reliable reversals in derived relations will require extensive experimental research across numerous studies. Nevertheless, given the apparent ease with which the IRAP produced such reversals, it could prove to be an important additional methodology for further research in this area.

The second important question generated by the current research pertains to why evidence for rule-persistence emerged in Experiment 3, but not in Experiment 2. The primary difference between these two experiments lay in the nature of the contingencies in the MTS blocks that followed the derived A-C reversals. That is, following the A-C reversals in Experiment 2, the MTS contingencies remained unchanged relative to the previous block of 
MTS trials (i.e., the A-C relations changed across blocks but MTS contingencies did not).

Following the A-C reversals in Experiment 3, however, the MTS contingencies also reversed and thus were consistent with the A-C reversals (for the first 15 trials); for the latter 15 trials, MTS contingencies reversed again and thus were now inconsistent with the A-C reversal. In effect, in Experiment 2, all MTS contingencies remained the same throughout the experiment, but in Experiment 3, these contingencies switched at numerous points throughout.

One potentially interesting observation at this point is that in Experiment 2, during the MTS blocks that followed the A-C reversal test, all participants emitted one response consistent with the reversed derived relation before responding in accordance with the task contingencies (i.e., responding in opposition with the reversed A-C rule). In other words, participants emitted one response in line with the reversed derived relation before 'contacting' that response contingent feedback was not coherent with the Training-IRAP contingencies. Research in other settings has also observed response patterns in which feedback from a single trial shifts patterns of responding (e.g., Vaughan, 1988; see also Galizio, 1979, for evidence of similar immediate shifts to contingency control). This first response suggests that the type of stimulus control experienced in the previous block of trials is extended to the current block, but is quickly adjusted upon encountering the negative/erroneous feedback. Interestingly, this may be relevant to patterns observed in Experiment 3.

Specifically, an interesting effect that emerged for Participant 1 in Experiment 3 was the somewhat weaker level of rule persistence than the other two participants. As noted earlier, relative to the other two participants, responding in the MTS block that followed the initial A-C reversal test block was more variable for Participant 1. Specifically, the Participant was the only one to emit two non-sequential incorrect responses in the first 15 trials of the MTS block (i.e., when the contingencies and the reversed derived rule were in line with one another). Thus, the participant had two opportunities to notice that incorrect responding 
resulted in a reduction of points. It is plausible, therefore, that these errors may have facilitated greater "tracking" of task contingencies after the contingency reversal, and indeed throughout the remainder of the task (note that the participant demonstrated virtually no persistence in rule-following in the second MTS block). Perhaps future research could explore the extent to which variability in responding in the initial MTS phase predicts sensitivity to detecting subsequent changing contingencies (cf. Hayes et al., 1986).

We should recognize that any interpretation of why evidence for rule-persistence was observed in the context of Experiment 3, but not Experiment 2, must remain relatively speculative at this point. One such interpretation, based on the HDML framework outlined in the introduction, could involve conceptualizing performance on the A-C derivation task as involving one relational network (or a derived rule), and performance on the MTS task as involving a second relational network (i.e., a rule generated by direct contact with the task contingencies). The key difference between Experiments 2 and 3 could thus be seen as involving changes in the relative coherence of the two networks.

Specifically, in Experiment 2, the MTS contingencies remained unchanged throughout, and thus the network could be defined as maximally coherent. As such, it provided a relatively strong source of behavioral control. In contrast, because the A-C relations reversed across blocks, the relative coherence of the A-C network was much reduced relative to the MTS network. In simple terms, participants responded in accordance with the most coherent network (i.e., the one that never changed), and consequently failed to show any evidence of rule-persistence in the face of competing MTS contingencies.

In contrast, in Experiment 3, the MTS contingencies changed within and across blocks, and thus, relative to Experiment 2, the coherence of the MTS-generated network was much reduced. As a result, the behavioral control properties of the reversed A-C derived relational network may have increased relative to Experiment 2 (because the network was 
now competing with an MTS network that also possessed some level of incoherence). Indeed, it could be argued that the coherence of the reversed A-C relational network in Experiment 3 increased relative to Experiment 2 because it cohered, at least initially, with the MTS contingencies following the A-C reversal itself. In effect, not only did the MTS network decrease in coherence, the reversed A-C network increased in coherence. Consequently, there were relatively clear examples of rule-persistence in Experiment 3.

In making this argument we are not suggesting that the relational responding did not cohere within Training-IRAP test blocks -- it clearly did because the A-C test performances were so often in accordance with the A-B/B-C training contingencies. Rather, we are suggesting that in Experiment 2 the multiple reversals in the baseline Training-IRAP contingencies undermined the behavioral control functions of the IRAP in the context of the MTS task. However, when the feedback contingencies overlapped across the Training-IRAP and MTS (initially) in Experiment 3, the coherence across the two networks increased and thus rule-following (based on the IRAP training and testing) persisted on the MTS task. In broad terms, one might argue there was greater behavioral momentum (e.g., Nevin et al., 1983) for rule-persistence in Experiment 3 because there was increased coherence in the reinforcement histories across the relational networks.

At this point, it is important to acknowledge a number of limitations in the current research. First, the number of MTS trials that were used to assess rule-persistence was relatively limited (i.e., 15 trials). It remains to be determined just how persistent, persistentrule following may be in the face of competing contingencies (see Harte et al. 2017, 2018, 2020b, and Bern et al., 2020, for group design research which provided participants with 50 trials to assess rule-persistence). Second, it should be acknowledged that differences in rulepersistence were observed across two experiments with only three participants in each experiment. Nevertheless, all three participants in Experiment 3 demonstrated greater rule- 
persistence than all three participants in Experiment 2, and at the very least, this finding is clearly worthy of replication and further research.

In closing, it is worth noting that, as far as we are aware, this is the first time that research examining the dynamics involved in derived persistent rule-following has been extended to a single-participant context. Interestingly, there have been recent calls to focus on the processes of change in the understanding and treatment of human psychological suffering, and critically, this work should involve a far heavier reliance on idiographic analyses (Hayes et al., 2019). In this light, the current research could be seen as particularly timely in that it focused on behavioural change at the individual participant level in a domain that has been strongly linked with psychological suffering (e.g., Zettle \& Hayes, 1989; Hayes et al., 1999; but see also Kissi et al., 2020). For example, one of the conclusions arising from the current study was that coherence between the reversed derived rule and the MTS contingencies was necessary before any impact of the reversed derivation was observed. In translating the potential implications of this finding to therapy, imagine a client who is given a new rule to follow (e.g., doing a gentle workout even when in pain can be beneficial in the context of chronic pain). Perhaps the client may need to repeatedly experience using this rule, and receive negative reinforcement for doing so (i.e., a reduction in pain following the workout), before learning to follow the therapist's advice in the natural environment. Indeed, research in other areas has also focused on rigid rule-following when rules were initially reinforced. For example, research exploring persistent rule-following in the context of gambling has found that accurate and inaccurate (or no explicit rule) differentially impacted upon participant risktaking behaviour/misguided gambling beliefs (e.g., Dixon, 2000; Dixon et al., 2000). Future research could combine some of the procedures adopted by Dixon and colleagues with the procedures and conceptual analyses reported here to advance the translational research agenda. Overall, therefore, it appears that combining both basic and applied research on 
persistent rule-following, which involves derived relational responding, with analyses at the individual participant level, could clearly be of benefit. 


\section{References}

Arantes, A. \& de Rose, J.C. (2015). High probability of equivalence class formation with both sample-s+ and sample-s- controlling relations in baseline. The Psychological Record, 65, 743-748. https//:doi.org/10.1007/s40732-015-0143-2

Barnes-Holmes, D., Barnes-Holmes, Y., Luciano, C., \& McEnteggart, C. (2017). From IRAP and REC model to a multi-dimensional multi-level framework for analyzing the dynamics of arbitrarily applicable relational responding. Journal of Contextual Behavioral Science, 6(4), 473-483. https//:doi.org/10.1016/j.jcbs.2017.08.001

Barnes-Holmes, D., Barnes-Holmes, Y., \& McEnteggart, C. (2020). Updating RFT (more field than frame) and its implications for process-based therapy. The Psychological Record. https//:doi.org/10.1007/s40732-019-00372-3

Belisle, J. \& Dixon, M.R. (2020). An exploratory analysis of relational density theory: Relational resistance and gravity. Journal of Contextual Behavioral Science, 16, 8095. https//:doi.org/10.1016/j.jcbs.2020.01.013

Belisle, J. \& Dixon, M.R. (2020). Relational density theory: Nonlinearity of Equivalence relating examined through higher-order volumetric-mass-density. Perspectives on Behavior Science, 43, 259-283. https//:doi.org/10.1007/s40614-020-00248-w

Bern, R., Persdotter, T., Harte, C., \& Barnes-Holmes, D. (2020). Relational coherence and persistent rule-following: The impact of targeting coherence in a 'non-critical' component of a relational network. The Psychological Record. Advance online publication. https//:doi.org/10.1007/s40732-020-00414-1 
Carrigan, P.F. \& Sidman, M. (1992). Conditional discrimination and equivalence relations: A theoretical analysis of control by negative stimuli. Journal of Experimental Analysis of Behavior, 58, 183-204. https//:doi.org/10.1901/jeab.1992.58-183

de Almeida, J.H. \& de Rose, J.C. (2015). Changing the meaningfulness of abstract stimuli by the reorganization of equivalence classes: Effects of delayed matching. The Psychological Record, 65, 451-461. https//:doi.org/10.1007/s40732-015-0120-9

de Rose, J.C., Hidalgo, M., \& Vasconcellos, M. (2013). Controlling relations in baseline conditional discriminations as determinants of stimulus equivalence. The Psychological Record, 63, 85-98. https//:doi.org/10.11133/j.tpr.2013.63.1.007

Dixon, M.R. (2000). Manipulating the illusion of control: Variations in gambling as a function of perceived control over chance outcomes. The Psychological Record, 50, 705-719. https//:doi.org/10.1007/BF03395379

Dixon, M., R., Hayes, L.J., \& Aban, I.B. (2000). Examining the toles of rule following, reinforcement, and preexperimental histories on risk-taking behavior. The Psychological Record, 50, 687-704. https//:doi.org/10.1007/BF03395378

Galizio, M. (1979). Contingency-shaped and rule-governed behavior: Instructional control of human loss avoidance. Journal of the Experimental Analysis of Behavior, 31(1), 5370. https//:doi.org/10.1901/jeab.1979.31-53

Garotti, M. \& de Rose, J.C. (2007). Reorganization of equivalence classes: Evidence for contextual control by baseline reviews before probes. The Psychological Record, 57, 87-102. https//:doi.org/10.1007/BF03395566 
Garotti, M., de Souza, D.G., de Rose, J.C., Molina, R.C., \& Gil, M.S.A. (2000).

Reorganization of equivalence classes after reversal of baseline relations. The Psychological Record, 50, 35-48. https//:doi.org/10.1007/BF03395341

Harte, C., Barnes-Holmes, D, Barnes-Holmes, Y., \& Kissi, A. (2020a). The study of rulegoverned behavior and derived stimulus relations: Bridging the gap. Perspectives on Behavior Science, 43, 361-385. https//:doi.org/10.1007/s40614-020-00256-w

Harte, C., Barnes-Holmes, D., Barnes-Holmes, Y., \& McEnteggart, C. (2018). The impact of high versus low levels of derivation for mutually and combinatorially entailed relations on persistent rule-following. Behavioural Processes, 157, 36-46. https//:doi.org/10.1016/j.beproc.2018.08.005.

Harte, C., Barnes-Holmes, Y., Barnes-Holmes, D., \& McEnteggart, C. (2017). Persistent rulefollowing in the face of reversed reinforcement contingencies: The differential impact of direct versus derived rules. Behavior Modification, 41(6), 743-763. https//:doi.org/10.1177/0145445517715871.

Harte, C., Barnes-Holmes, D., Barnes-Holmes, Y., McEnteggart, C., Gys, J., Hassler, C. (2020b). Exploring the potential impact of relational coherence on persistent rulefollowing: The first study. Learning and Behavior, 48, 373-391. https//:doi.org/10.3758/s13420-019-00399-0

Hayes, S. C., Barnes-Holmes, D, \& Roche, B. (2001). Relational frame theory: A postSkinnerian account of human language and cognition. Plenum.

Hayes, S.C., Brownstein, A.J., Haas, J.R., \& Greenway, D.E. (1986). Instructions, multiple schedules, and extinction: Distinguishing rule-governed from schedule-controlled behavior. Journal of Experimental Analysis of Behavior, 46, 137-147. https//:doi.org/10.1901/jeab.1986.46-137 
Hayes, S.C. \& Hayes, L.J. (1989). The verbal action of the listener as a basis for rulegovernance. In S.C. Hayes (Ed.), Rule-governed behavior: Cognition, contingencies, and instructional control (pp. 153-190). Plenum.

Hayes, S.C., Hofmann, S.G., Stanton, C.E., Carpenter, J.K., Sanford, B.T., Curtiss, J.E., \& Ciarrochi, J. (2019). The role of the individual in the coming era of process-based therapy. Behavior Research and Therapy, 117, 40-53. https//:doi.org/10.1016/j.brat.2018.10.005

Hayes, S. C., Strosahl, K., \& Wilson, K.G. (1999). Acceptance and Commitment Therapy: An experiential approach to behavior change. Guilford Press.

Johnson, C. \& Sidman, M. (1993). Conditional discrimination and equivalence relations: Control by negative stimuli. Journal of the Experimental Analysis of Behavior, 59, 333-347. https//:doi.org/10.1901/jeab.1993.49-333

Kissi, A., Harte, C., Hughes, S., De Houwer, J., \& Crombez, G. (2020). The rule-based insensitivity effect: A systematic review. Peer J. Advance online publication. https//:doi.org/10.7717/peerj.9496

Leech, A. \& Barnes-Holmes, D. (2020). Training and testing for a transformation of fear and avoidance functions via combinatorial entailment using the implicit relational assessment procedure (IRAP): Further exploratory analyses. Behavioural Processes, 172. https//:doi.org/10.1016/j.beproc.2019.104027

Nevin, J.A., Mandell, C., \& Atak, J.R. (1983). The analysis of behavioral momentum. Journal of Experimental Analysis of Behavior, 39, 49-59. https//:doi.org/10.1901/jeab.1983.39-40

O’Hora, D., Barnes-Holmes, D., Roche, B., \& Smeets, P. M. (2004). Derived relational networks and control by novel instructions: A possible model of generative verbal 
responding. The Psychological Record, 54, 437-460.

https//:doi.org/10.1007/BF03395484

O’Hora, D., Barnes-Holmes, D., \& Stewart, I. (2014). Antecedent and consequential control of derived instruction-following. Journal of the Experimental Analysis of Behavior, 102 (1), 66-85. https//:doi.org/10.1002/jeab.95.

Perez, W.F., Tomanari, G.Y., \& Vaidya, M. (2017). Effects of heterogenous controlling relations on tests of transitivity and equivalence: An exploratory study. European Journal of Behavior Analysis, 18, 251-263.

https//:doi.org/10.1080/15021149.2017.1309957.

Perez, W.F., Tomanari, G.Y., \& Vaidya, M. (2015). Effects of select and reject control on equivalence class formation and transfer of function. Journal of the Experimental Analysis of Behavior, 104, 146-166. https//:doi.org/10.1002/jeab.164.

Pilgrim, C. \& Galizio, M. (1995). Reversal of baseline relations and stimulus equivalence: I. Adults. Journal of the Experimental Analysis of Behavior, 63, 225-238. https//:doi.org/10.1901/jeab.1995.63-225

Pilgrim, C., Chambers, L., \& Galizio, M. (1995). Reversal of baseline relations and stimulus equivalence: II. Children. Journal of the Experimental Analysis of Behavior, 63, 239254. https//:doi.org/10.1901/jeab.1995.63-239

Pilgrim, C. \& Galizio, M. (1990). Relations between baseline contingencies and equivalence probe performances. Journal of the Experimental Analysis of Behavior, 54, 213-224. https//:doi.org/10.1901/jeab.1990.54-213

Sidman, M. (1971). Reading and auditory-visual equivalences. Journal of Speech, Language, and Hearing Research, 14, 5-13. https//:doi.org/10.1044/jshr.1401.05

Sidman, M. (1994). Equivalence relations and behavior: A research story. Authors Cooperative. 
Skinner, B.F. (1966). An operant analysis of problem solving. In B. Keinmuntz (Eds.), Problem-solving: Research, method, and therapy (pp. 225-257). Wiley.

Smeets, P.M., Barnes-Holmes, Y., Akpinar, D., \& Barnes-Holmes, D. (2003). Reversal of equivalence relations. The Psychological Record, 53, 91-119.

Vaughan, W. (1988). Formation of equivalence sets in pigeons. Journal of Experimental Psychology: Animal Behavior Processes, 14(1), 36-42. https//:doi.org/10.1037/00977403.14.1.36

Weiner, H. (1969). Controlling human fixed-interval performance. Journal of the Experimental Analysis of Behavior, 12, 349-373. https//:doi.org/10.1901/jeab.1969.12-349

Weiner, H. (1964). Conditioning history and human fixed-interval performance. Journal of the Experimental Analysis of Behavior, 7, 383-385. https//:doi.org/10.1901/jeab.1964.7-383

Zettle, R.D. \& Hayes, S.C. (1982). Rule-governed behavior: A potential theoretical framework for cognitive-behavior therapy. In P.C. Kendall (Ed.), Advances in cognitive-behavioral research and therapy (Vol. 1: pp. 73-118). Academic. 
Table 1

Stimulus sets employed in each Derivation Pre-Training Task cycle

\begin{tabular}{cccccc}
\hline \multicolumn{7}{c}{ Stimuli: Derivation Pre-Training Task } \\
\hline Set 1 & Set 2 & Set 3 & Set 4 & Set 5 & Set 6 \\
\hline Livro & Rato & Menino & Quadro & Cachorro & Árvore \\
Libro & Raton & Niño & Cuadro & XXX & //I/ \\
Leabhar & Luch & Buachail & Frama & Madra & Crann \\
\hline
\end{tabular}


Table 2

Stimulus sets employed within the Training IRAP

\begin{tabular}{cc}
\hline \multicolumn{2}{c}{ Stimuli: Training IRAPs } \\
\hline Set 7 & Set 8 \\
\hline Least Similar & Most Similar \\
(Menos Parecido) & (Mais Parecido) \\
TTT & ]$][[$ \\
Beda & Sarua \\
\hline
\end{tabular}


Table 3

Stimulus combinations employed within each block of trials in each cycle of the Derivation Pre-Training task. Each cell represents an individual trial

\begin{tabular}{|c|c|c|c|}
\hline & \multicolumn{3}{|c|}{ Cycle 1} \\
\hline Relation Type & $\begin{array}{l}\text { Phase } 1 \\
\text { Set } 1\end{array}$ & $\begin{array}{l}\text { Phase } 2 \\
\text { Set } 2\end{array}$ & $\begin{array}{l}\text { Phase 3 } \\
\text { Sets } 1+2\end{array}$ \\
\hline $\begin{array}{l}\text { (Likely)Known } \\
\text { Relations }\end{array}$ & Livro $=$ Libro & Rato $=$ Raton & $\begin{array}{l}\text { Livro } \neq \text { Raton } \\
\text { Rato } \neq \text { Libro }\end{array}$ \\
\hline Trained Relations & Libro = Leabhar & Raton $=$ Luch & $\begin{array}{l}\text { Libro } \neq \text { Luch } \\
\text { Raton } \neq \text { Madra }\end{array}$ \\
\hline \multirow[t]{3}{*}{ Derived Relations } & $\begin{array}{l}\text { Livro = Leabhar } \\
\text { Leabhar }=\text { Livro }\end{array}$ & $\begin{array}{l}\text { Rato }=\text { Luch } \\
\text { Luch }=\text { Rato }\end{array}$ & $\begin{array}{l}\text { Livro } \neq \text { Luch } \\
\text { Rato } \neq \text { Madra }\end{array}$ \\
\hline & \multicolumn{3}{|c|}{ Cycle 2} \\
\hline & $\begin{array}{l}\text { Phase } 1 \\
\text { Set } 3\end{array}$ & $\begin{array}{l}\text { Phase } 2 \\
\text { Set } 4\end{array}$ & $\begin{array}{l}\text { Phase } 3 \\
\text { Sets } 3+4\end{array}$ \\
\hline $\begin{array}{l}\text { (Likely)Known } \\
\text { Relations }\end{array}$ & Menino $=$ Niño & Quadro = Cuadro & $\begin{array}{l}\text { Menino } \neq \text { F Cuadro } \\
\text { Quadro } \neq \text { Niño }\end{array}$ \\
\hline Trained Relations & Niño = Buachail & Cuadro $=$ Frama & $\begin{array}{l}\text { Niño } \neq \text { Buideal } \\
\text { Cuadro } \neq \text { Frama }\end{array}$ \\
\hline \multirow[t]{3}{*}{ Derived Relations } & $\begin{array}{l}\text { Menino = Buachail } \\
\text { Buachail = Menino }\end{array}$ & $\begin{array}{l}\text { Quadro = Frama } \\
\text { Frama = Quadro }\end{array}$ & $\begin{array}{l}\text { Menino } \neq \text { Frama } \\
\text { Quadro } \neq \text { Buachail }\end{array}$ \\
\hline & \multicolumn{3}{|c|}{ Cycle 3} \\
\hline & $\begin{array}{l}\text { Phase 1 } \\
\text { Set } 5\end{array}$ & $\begin{array}{l}\text { Phase } 2 \\
\text { Set } 6\end{array}$ & $\begin{array}{l}\text { Phase } 3 \\
\text { Sets } 5+6\end{array}$ \\
\hline Trained Relations & Cachorro $=\mathrm{XXX}$ & Árvore $=/ / / /$ & $\begin{array}{l}\text { Cachorro } \neq / / / / \\
\text { Árvore } \neq \text { XXX }\end{array}$ \\
\hline Trained Relations & $\mathrm{XXX}=$ Madra & $/ / / /=$ Crann & $\begin{array}{l}\text { XXX } \neq \text { Crann } \\
/ / / / \neq \text { Madra }\end{array}$ \\
\hline Derived Relations & $\begin{array}{l}\text { Cachorro = Madra } \\
\text { Madra = Cachorro }\end{array}$ & $\begin{array}{l}\text { Árvore }=\text { Crann } \\
\text { Crann }=\text { Árvore }\end{array}$ & $\begin{array}{l}\text { Cachorro } \neq \text { Crann } \\
\text { Árvore } \neq \text { Madra }\end{array}$ \\
\hline
\end{tabular}




\section{Table 4}

A breakdown of the numbers of training blocks required by each participant to successfully reach the performance criteria during baseline and

reversal relation training on the Training IRAP

\begin{tabular}{|c|c|c|c|c|c|c|c|c|c|c|c|c|c|c|c|c|c|c|}
\hline \multicolumn{19}{|c|}{ Experiment 1} \\
\hline & \multicolumn{3}{|c|}{ Baseline 1} & \multicolumn{3}{|c|}{ Reversal 1} & \multicolumn{3}{|c|}{ Baseline 2} & \multicolumn{3}{|c|}{ Reversal 2} & \multicolumn{2}{|c|}{ Baseline 3} & \multicolumn{4}{|c|}{ Reversal 3} \\
\hline & $A-B$ & $B-C$ & $\begin{array}{c}\text { Mixed } \\
A-B / B-C\end{array}$ & $A-B$ & $B-C$ & $\begin{array}{c}\text { Mixed } \\
A-B / B-C\end{array}$ & $A-B$ & $B-C$ & $\begin{array}{c}\text { Mixed } \\
A-B / B-C\end{array}$ & $A-B$ & $B-C$ & $\begin{array}{c}\text { Mixed } \\
A-B / B-C\end{array}$ & $A-B$ & $B-C$ & $\begin{array}{l}\text { Mixed } \\
A-B / B-C\end{array}$ & $A-B$ & $B-C$ & $\begin{array}{l}\text { Mixed } \\
A-B / B-C\end{array}$ \\
\hline Participant 1 & 1 & 2 & 2 & 1 & 1 & 2 & 1 & 1 & 1 & 1 & 2 & 1 & 1 & 1 & 1 & 1 & 1 & 1 \\
\hline Participant 2 & 1 & 3 & 1 & 1 & 1 & 2 & 1 & 1 & 1 & 1 & 2 & 1 & 1 & 1 & 1 & 1 & 1 & 1 \\
\hline Participant 3 & 2 & 1 & 1 & 1 & 1 & 1 & 1 & 1 & 1 & 1 & 1 & 1 & 1 & 1 & 1 & 1 & 1 & 1 \\
\hline \multicolumn{19}{|c|}{ Experiment 2} \\
\hline & \multicolumn{3}{|c|}{ Baseline 1} & \multicolumn{3}{|c|}{ Reversal 1} & \multicolumn{3}{|c|}{ Baseline 2 } & \multicolumn{3}{|c|}{ Reversal 2} & \multicolumn{2}{|c|}{ Baseline 3} & & \multicolumn{3}{|c|}{ Reversal 3} \\
\hline & $A-B$ & $B-C$ & $\begin{array}{c}\text { Mixed } \\
A-B / B-C\end{array}$ & $A-B$ & $B-C$ & $\begin{array}{c}\text { Mixed } \\
A-B / B-C\end{array}$ & $A-B$ & $B-C$ & $\begin{array}{c}\text { Mixed } \\
A-B / B-C\end{array}$ & $A-B$ & $B-C$ & $\begin{array}{c}\text { Mixed } \\
A-B / B-C\end{array}$ & $A-B$ & $B-C$ & $\begin{array}{l}\text { Mixed } \\
A-B / B-C\end{array}$ & $A-B$ & $B-C$ & $\begin{array}{l}\text { Mixed } \\
A-B / B-C\end{array}$ \\
\hline Participant 1 & 2 & 1 & 1 & 1 & 1 & 1 & 1 & 1 & 1 & 1 & 1 & 1 & 1 & 1 & 1 & 1 & 1 & 1 \\
\hline Participant 2 & 2 & 2 & 1 & 2 & 1 & 1 & 1 & 1 & 1 & 1 & 1 & 2 & 1 & 2 & 1 & 2 & 1 & 1 \\
\hline Participant 3 & 2 & 1 & 1 & 1 & 1 & 1 & 1 & 1 & 1 & 1 & 1 & 1 & 2 & 3 & 1 & 1 & 1 & 2 \\
\hline \multicolumn{19}{|c|}{ Experiment 3} \\
\hline & \multicolumn{3}{|c|}{ Baseline 1} & \multicolumn{3}{|c|}{ Reversal 1} & \multicolumn{3}{|c|}{ Baseline 2 } & \multicolumn{3}{|c|}{ Reversal 2} & & & & & & \\
\hline & $A-B$ & $B-C$ & $\begin{array}{c}\text { Mixed } \\
A-B / B-C\end{array}$ & $A-B$ & $B-C$ & $\begin{array}{c}\text { Mixed } \\
A-B / B-C\end{array}$ & $A-B$ & $B-C$ & $\begin{array}{c}\text { Mixed } \\
A-B / B-C\end{array}$ & $A-B$ & $B-C$ & $\begin{array}{c}\text { Mixed } \\
A-B / B-C\end{array}$ & & & & & & \\
\hline Participant 1 & 2 & 1 & 1 & 1 & 1 & 1 & 1 & 1 & 1 & 1 & 1 & 1 & & & & & & \\
\hline Participant 2 & 2 & 1 & 1 & 3 & 1 & 1 & 1 & 1 & 1 & 1 & 1 & 1 & & & & & & \\
\hline Participant 3 & 2 & 1 & 1 & 2 & 1 & 2 & 1 & 2 & 1 & 1 & 1 & 1 & & & & & & \\
\hline
\end{tabular}




\section{Figure 1}

$A-B$ baseline relation training block trial-types
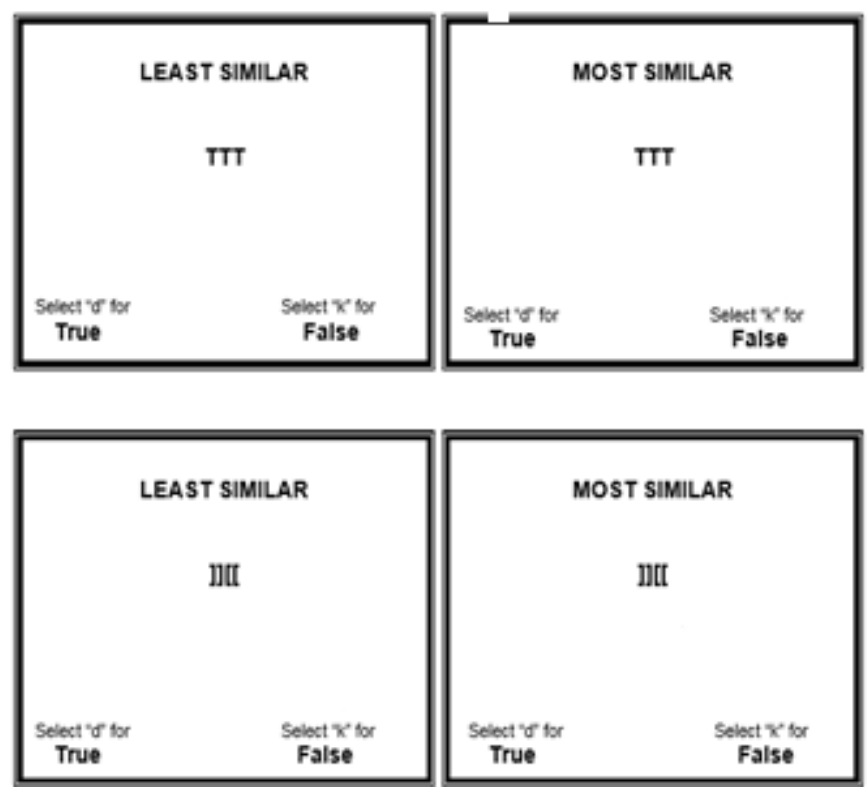

Note. Diagrammatic representation of the trial-types that appear in the A-B relation training block. The four trial-types were denoted as: Least Similar-TTT, Most Similar-TTT, Least Similar-]][[, Most Similar-]][[. 


\section{Figure 2}

$B$-C baseline relation training block trial-types

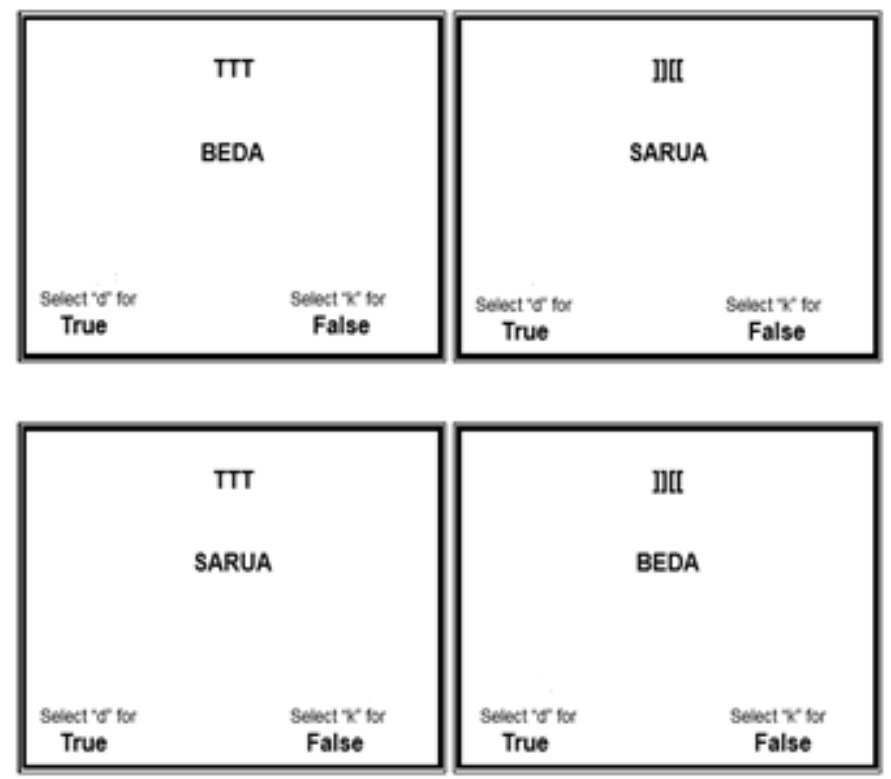

Note. Diagrammatic representation of the trial-types that appear in the B-C relation training block. The four trial-types were denoted as: TTT-Beda, ]][[-Sarua, TTT-Sarua, ]][[-Beda. 


\section{Figure 3}

Derived A-C relation test block trial-types

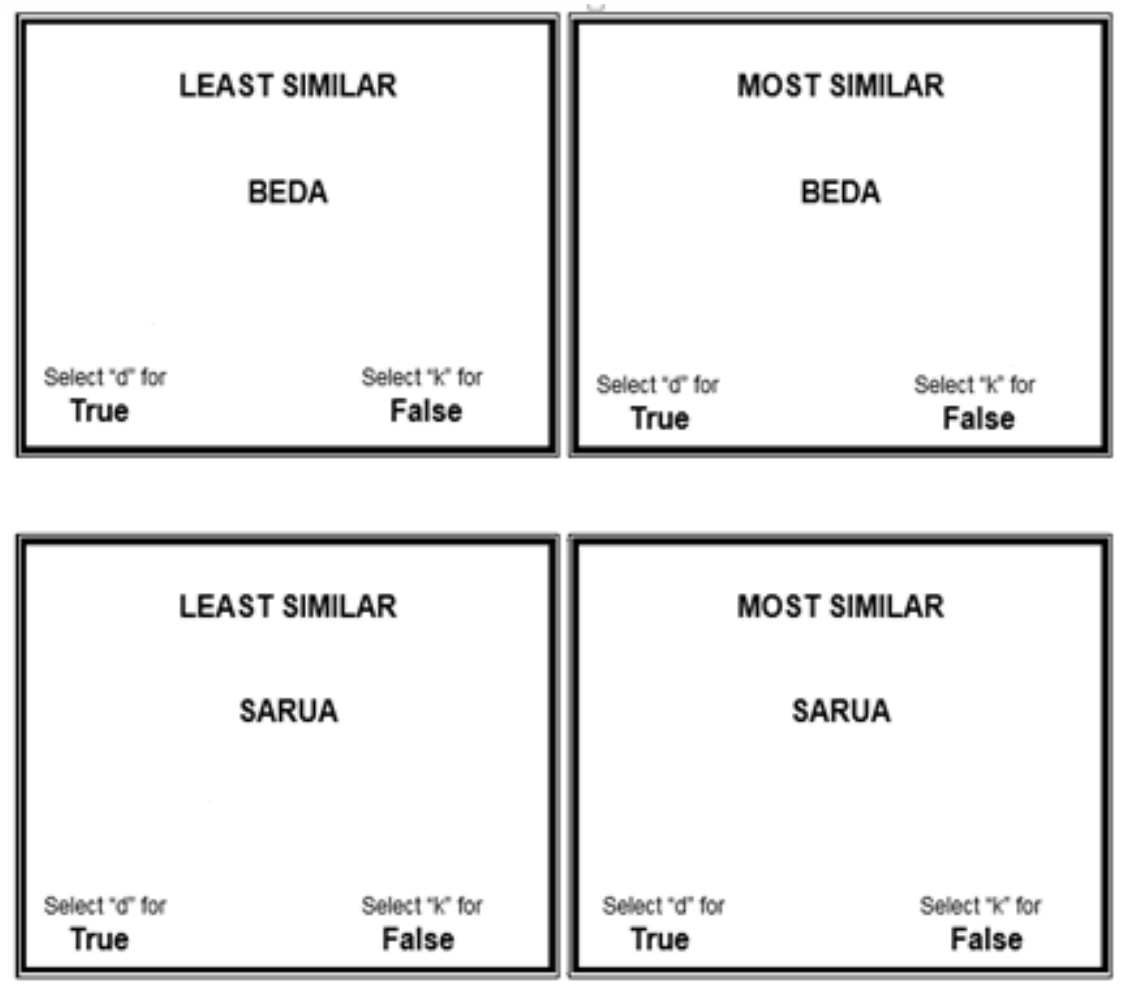

Note. Diagrammatic representation of the trial-types that appear in the derived A-C relation test block. The four trial-types were denoted as: Least Similar-Beda, Most Similar-Beda, Least Similar-Sarua, Most Similar-Sarua. 


\section{Figure 4}

Experimental Sequence

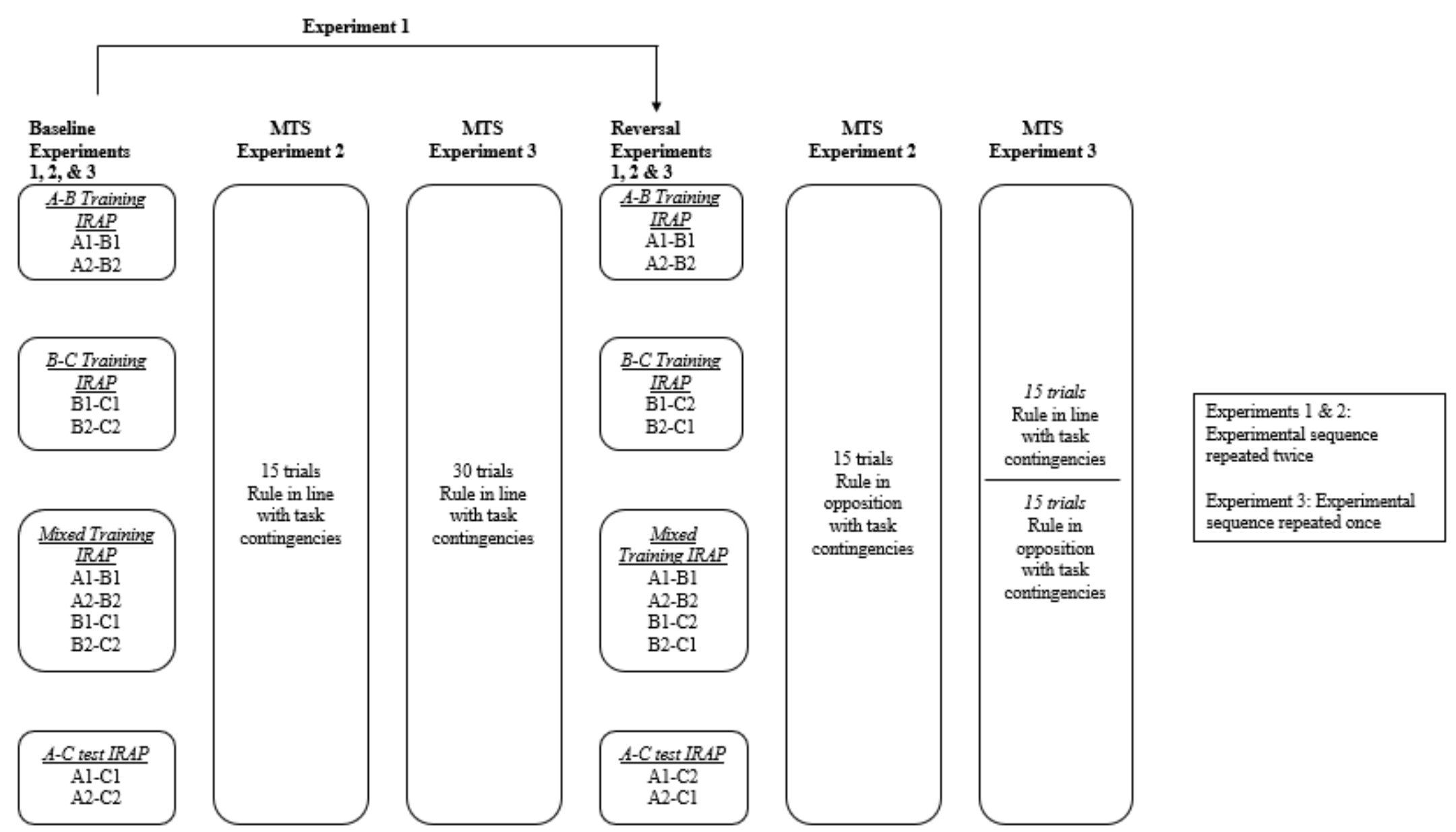

Note. An illustration of the experimental sequence involved in Experiments 1, 2 and 3. 


\section{Figure 5}

Derived A-C performances (baseline and reversal) per trial-type per participant
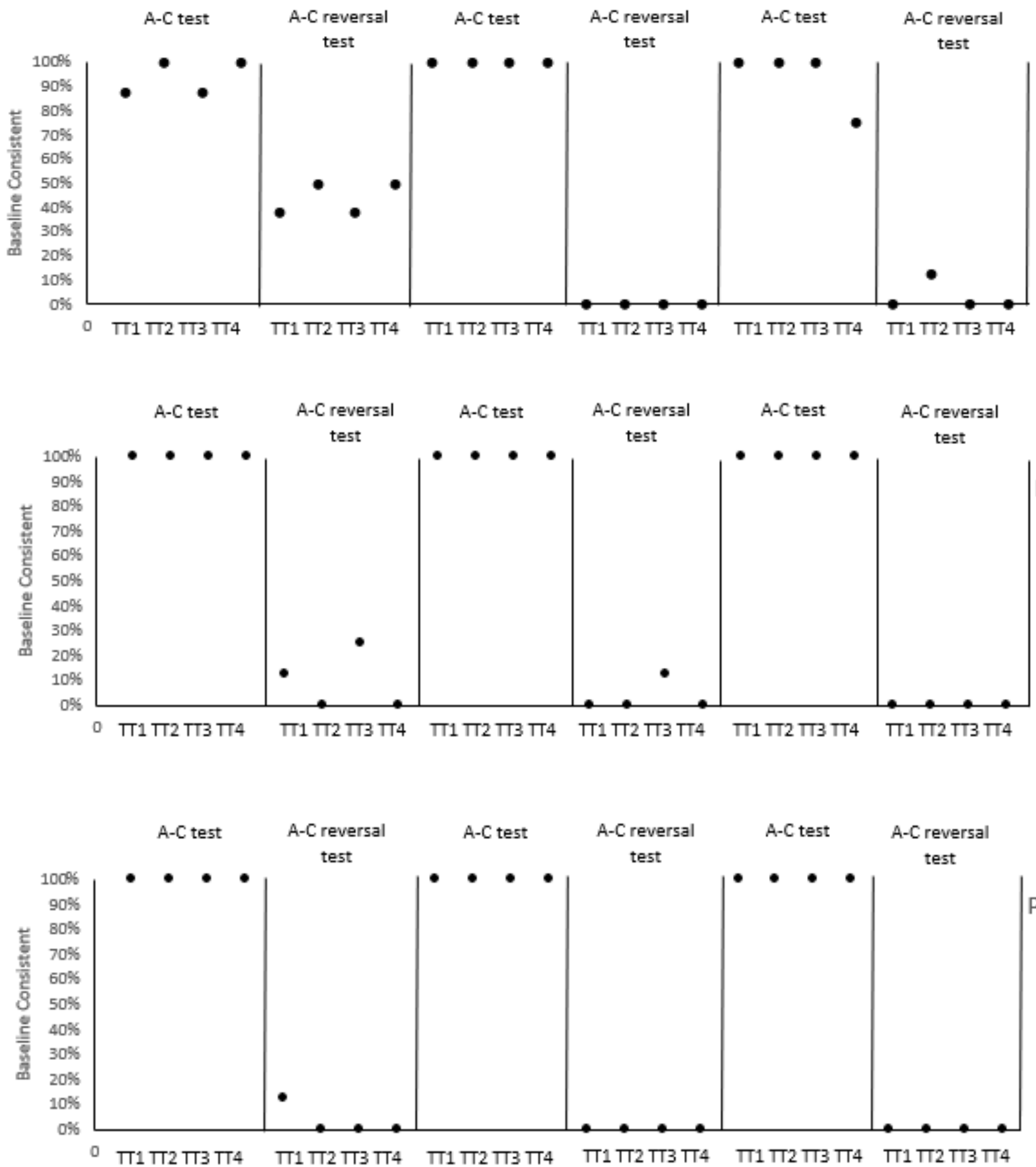

Participant 3 
Note. $\mathrm{Y}$ axis scores represent baseline consistent responding. Thus, A-C reversal scores of or near $0 \%$ represent reversal performances of or near $100 \%$. During A-C test blocks, trial-type scores refer to responding as follows: TT1 $=$ Least similar-Beda-True; TT2 = Most similarBeda-False; TT3 = Least similar-Sarua-False; TT4 = Most similar-Sarua-True. During A-C reversal test blocks, trial-type scores refer to responding as follows: TT1 = Least similarSarua-True; TT2 = Most similar-Sarua-False; TT3 = Least similar-Beda-False; TT4 = Most similar-Beda-True. 
Figure 6

Sample MTS stimulus set

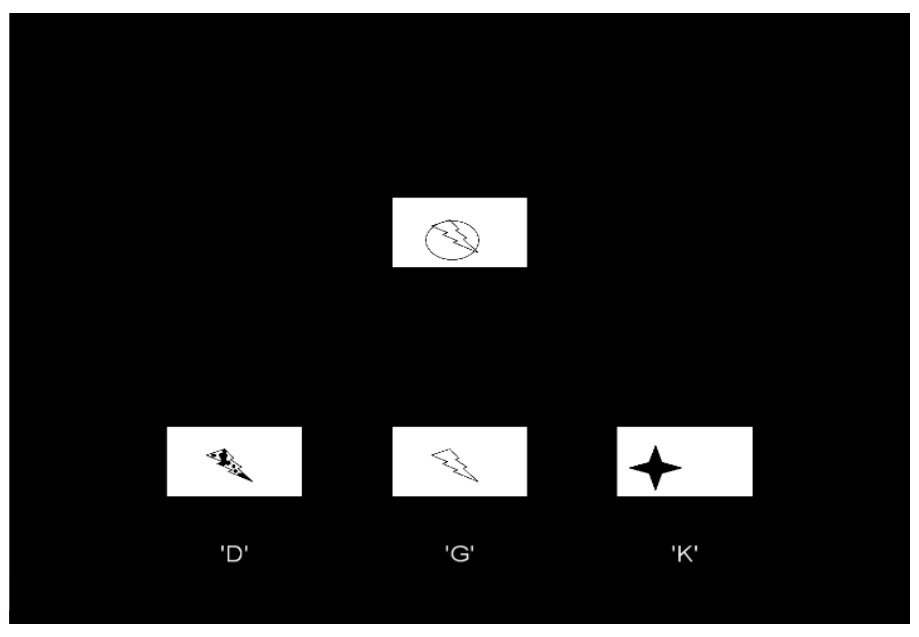

Note. An example of a single trial and stimulus set presented in the MTS task. 


\section{Figure 7}

Derived A-C test and MTS performances per participant in Experiment 2
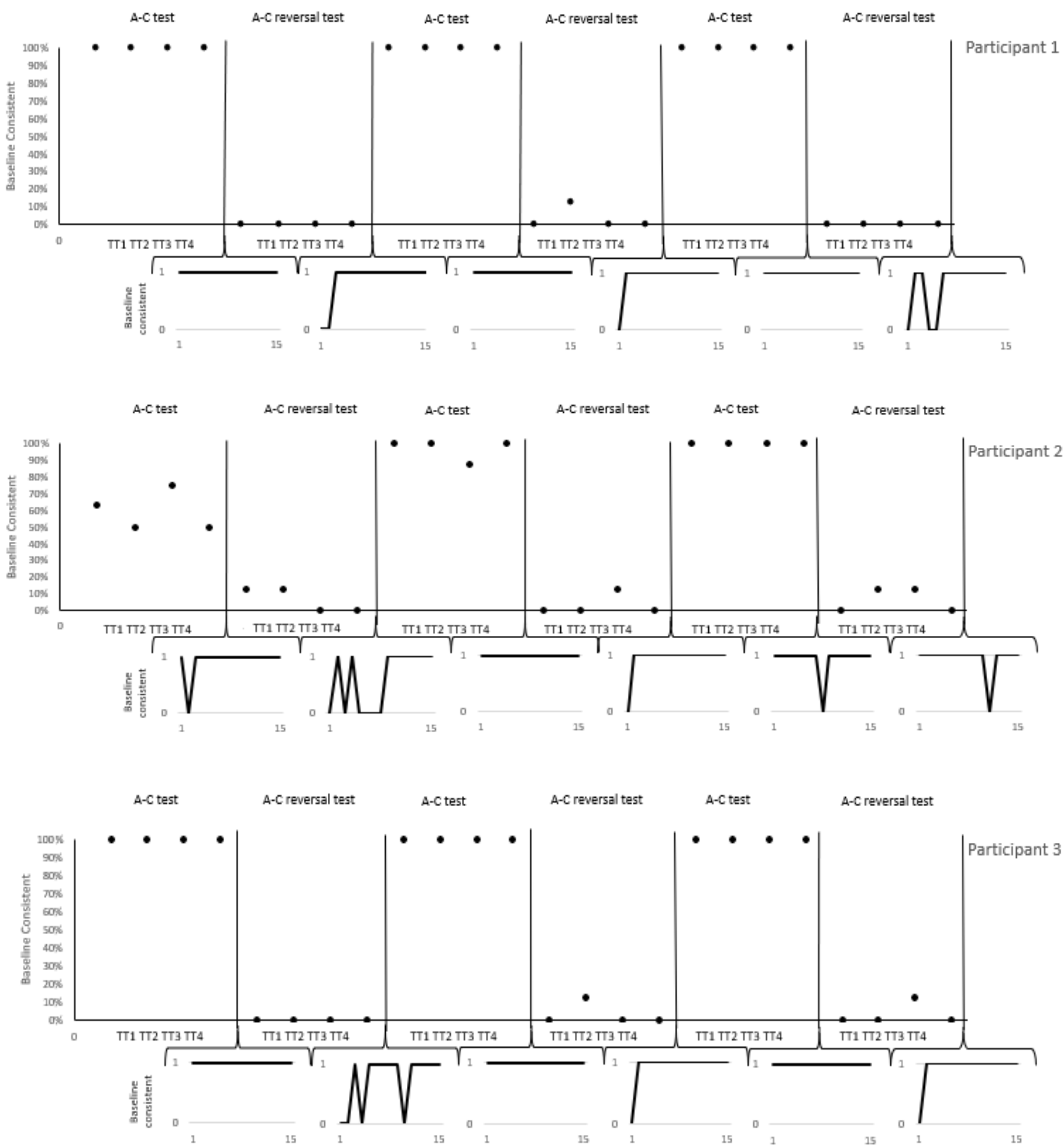
Note. As in Experiment 1, graphs above represent derived A-C IRAP test performances. Once again, during A-C test blocks, trial-type scores refer to responding as follows: $\mathrm{TT} 1=$ Least similar-Beda-True; TT2 = Most similar-Beda-False; TT3 = Least similar-Sarua-False; TT4 = Most similar-Sarua-True. During A-C reversal test blocks, trial-type scores refer to responding as follows: TT1 $=$ Least similar-Sarua-True; TT2 = Most similar-Sarua-False; TT3 = Least similar-Beda-False; TT4 = Most similar-Beda-True. Graphs presented below IRAP test performances represent participant MTS performances that followed each A-C baseline and A-C reversal test. Scores of 1 represent responding in accordance with the baseline derived A-C rule. Scores of 0 represent responding in accordance with the reversed derived A-C rule. 
Figure 8

Derived A-C test and MTS performances per participant in Experiment 3
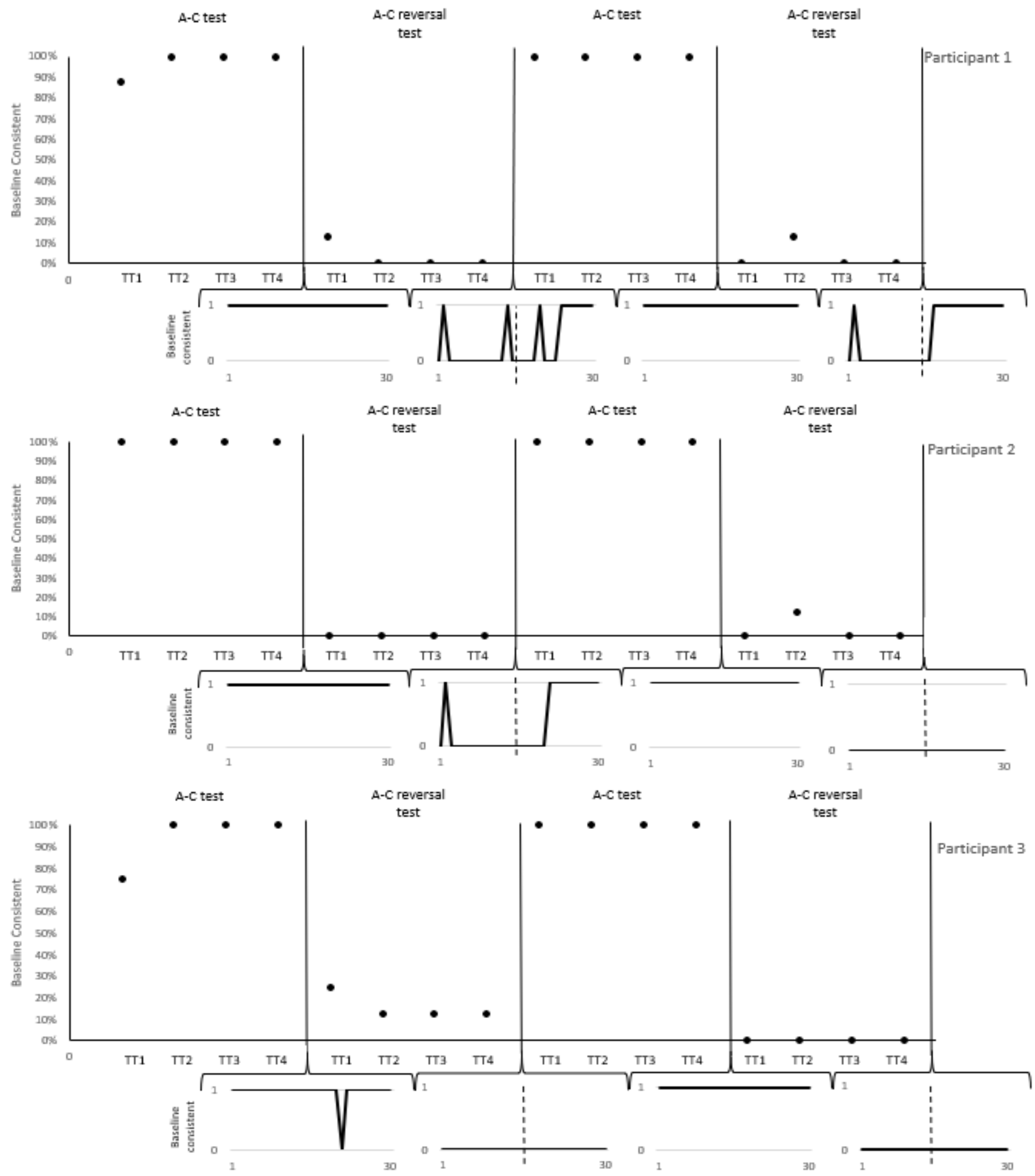
Note. As in Experiments 1 and 2, graphs above represent derived A-C IRAP test performances. Once again, during A-C test blocks, trial-type scores refer to responding as follows: TT1 = Least similar-Beda-True; TT2 = Most similar-Beda-False; TT3 = Least similar-Sarua-False; TT4 = Most similar-Sarua-True. During A-C reversal test blocks, trialtype scores refer to responding as follows: TT1 = Least similar-Sarua-True; TT2 = Most similar-Sarua-False; TT3 = Least similar-Beda-False; TT4 = Most similar-Beda-True. Similar to Experiment 2, performances below represent participant MTS performances that followed each A-C baseline and A-C reversal test. Scores of 1 represent responding in accordance with the baseline derived A-C rule. Scores of 0 represent responding in accordance with reversed derived A-C rule. In addition, graphs with a broken line represent the point at which contingencies reversed during these MTS blocks. Graphs without such a line represent MTS blocks that involved no contingency reversal. 


\section{Appendix A}

Participants' accuracy scores per trial-type (TT) per baseline and reversal training block

within the block in which performance criteria was reached:

\begin{tabular}{|c|c|c|c|c|c|c|c|c|c|c|c|c|}
\hline \multicolumn{13}{|c|}{ Experiment 1 } \\
\hline & \multicolumn{4}{|c|}{ Participant 1} & \multicolumn{4}{|c|}{ Participant 2} & \multicolumn{4}{|c|}{ Participant 3} \\
\hline & $T T 1$ & $T T 2$ & TT3 & $T T 4$ & TT1 & TT2 & $T T 3$ & TT4 & $T T 1$ & $T T 2$ & TT3 & TT4 \\
\hline Baseline 1: A-B & $5 / 6$ & $6 / 6$ & $6 / 6$ & $6 / 6$ & $6 / 6$ & $6 / 6$ & $5 / 6$ & $5 / 6$ & $6 / 6$ & $6 / 6$ & $5 / 6$ & $5 / 6$ \\
\hline Baseline 1: B-C & $5 / 6$ & $5 / 6$ & $5 / 6$ & $6 / 6$ & $6 / 6$ & $6 / 6$ & $6 / 6$ & $5 / 6$ & $6 / 6$ & $6 / 6$ & $6 / 6$ & $6 / 6$ \\
\hline $\begin{array}{l}\text { Baseline 1: } \\
\text { Mixed A-B/B-C }\end{array}$ & $8 / 8$ & $7 / 8$ & $8 / 8$ & $7 / 8$ & $8 / 8$ & $8 / 8$ & $8 / 8$ & $8 / 8$ & $8 / 8$ & $8 / 8$ & $7 / 8$ & $8 / 8$ \\
\hline Reversal 1: A-B & $6 / 6$ & $6 / 6$ & $5 / 6$ & $6 / 6$ & $5 / 6$ & $5 / 6$ & $5 / 6$ & $5 / 6$ & $6 / 6$ & $6 / 6$ & $6 / 6$ & $6 / 6$ \\
\hline Reversal 1: B-C & $6 / 6$ & $6 / 6$ & $5 / 6$ & $5 / 6$ & $6 / 6$ & $5 / 6$ & $6 / 6$ & $5 / 6$ & $6 / 6$ & $5 / 6$ & $6 / 6$ & $6 / 6$ \\
\hline $\begin{array}{l}\text { Reversal 1: } \\
\text { Mixed A-B/B-C }\end{array}$ & $7 / 8$ & $8 / 8$ & $8 / 8$ & $8 / 8$ & $8 / 8$ & $8 / 8$ & $8 / 8$ & $8 / 8$ & $8 / 8$ & $8 / 8$ & $7 / 8$ & $8 / 8$ \\
\hline Baseline 2: A-B & $6 / 6$ & $6 / 6$ & $6 / 6$ & $6 / 6$ & $6 / 6$ & $5 / 6$ & $6 / 6$ & $5 / 6$ & $6 / 6$ & $6 / 6$ & $5 / 6$ & $6 / 6$ \\
\hline Baseline 2: B-C & $6 / 6$ & $6 / 6$ & $6 / 6$ & $5 / 6$ & $6 / 6$ & $5 / 6$ & $5 / 6$ & $6 / 6$ & $6 / 6$ & $6 / 6$ & $5 / 6$ & $6 / 6$ \\
\hline $\begin{array}{l}\text { Baseline 2: } \\
\text { Mixed A-B/B-C }\end{array}$ & $8 / 8$ & $8 / 8$ & $8 / 8$ & $8 / 8$ & $8 / 8$ & $8 / 8$ & $8 / 8$ & $8 / 8$ & $8 / 8$ & $7 / 8$ & $7 / 8$ & $7 / 8$ \\
\hline Reversal 2: A-B & $5 / 6$ & $5 / 6$ & $6 / 6$ & $5 / 6$ & $5 / 6$ & $6 / 6$ & $6 / 6$ & $6 / 6$ & $6 / 6$ & $6 / 6$ & $6 / 6$ & $6 / 6$ \\
\hline Reversal 2: B-C & $6 / 6$ & $5 / 6$ & $6 / 6$ & $6 / 6$ & $6 / 6$ & $6 / 6$ & $5 / 6$ & $6 / 6$ & $6 / 6$ & $6 / 6$ & $5 / 6$ & $6 / 6$ \\
\hline $\begin{array}{l}\text { Reversal 2: } \\
\text { Mixed A-B/B-C }\end{array}$ & $8 / 8$ & $8 / 8$ & $8 / 8$ & $8 / 8$ & $8 / 8$ & $8 / 8$ & $8 / 8$ & $8 / 8$ & $8 / 8$ & $7 / 8$ & $8 / 8$ & $8 / 8$ \\
\hline Baseline 3: A-B & $6 / 6$ & $6 / 6$ & $5 / 6$ & $6 / 6$ & $6 / 6$ & $6 / 6$ & $6 / 6$ & $6 / 6$ & $6 / 6$ & $6 / 6$ & $6 / 6$ & $6 / 6$ \\
\hline Baseline 3: B-C & $6 / 6$ & $5 / 6$ & $6 / 6$ & $6 / 6$ & $6 / 6$ & $6 / 6$ & $6 / 6$ & $6 / 6$ & $6 / 6$ & $5 / 6$ & $5 / 6$ & $6 / 6$ \\
\hline $\begin{array}{l}\text { Baseline 3: } \\
\text { Mixed A-B/B-C }\end{array}$ & $8 / 8$ & $8 / 8$ & $7 / 8$ & $8 / 8$ & $8 / 8$ & $8 / 8$ & $8 / 8$ & $8 / 8$ & $8 / 8$ & $8 / 8$ & $8 / 8$ & $8 / 8$ \\
\hline Reversal 3: A-B & $6 / 6$ & $6 / 6$ & $6 / 6$ & $6 / 6$ & $6 / 6$ & $6 / 6$ & $6 / 6$ & $6 / 6$ & $6 / 6$ & $6 / 6$ & $6 / 6$ & $5 / 6$ \\
\hline Reversal 3: B-C & $6 / 6$ & $6 / 6$ & $6 / 6$ & $6 / 6$ & $6 / 6$ & $6 / 6$ & $6 / 6$ & $6 / 6$ & $6 / 6$ & $6 / 6$ & $6 / 6$ & $6 / 6$ \\
\hline $\begin{array}{l}\text { Reversal 3: } \\
\text { Mixed A-B/B-C }\end{array}$ & $7 / 8$ & $8 / 8$ & $7 / 8$ & $8 / 8$ & $8 / 8$ & $8 / 8$ & $8 / 8$ & $8 / 8$ & $8 / 8$ & $8 / 8$ & $8 / 8$ & $8 / 8$ \\
\hline
\end{tabular}

\begin{tabular}{|c|c|c|c|c|c|c|c|c|c|c|c|c|}
\hline \multicolumn{13}{|c|}{ Experiment 2} \\
\hline & \multicolumn{4}{|c|}{ Participant 1} & \multicolumn{4}{|c|}{ Participant 2} & \multicolumn{4}{|c|}{ Participant 3} \\
\hline & $T T 1$ & TT2 & TT3 & TT4 & $T T 1$ & $T T 2$ & TT3 & TT4 & $T T 1$ & $T T 2$ & TT3 & TT4 \\
\hline Baseline 1: A-B & $6 / 6$ & $6 / 6$ & $6 / 6$ & $6 / 6$ & $6 / 6$ & $6 / 6$ & $5 / 6$ & $6 / 6$ & $5 / 6$ & $5 / 6$ & $6 / 6$ & $5 / 6$ \\
\hline Baseline 1: B-C & $5 / 6$ & $6 / 6$ & $6 / 6$ & $5 / 6$ & $6 / 6$ & $5 / 6$ & $6 / 6$ & $5 / 6$ & $5 / 6$ & $6 / 6$ & $6 / 6$ & $6 / 6$ \\
\hline $\begin{array}{l}\text { Baseline 1: } \\
\text { Mixed A-B/B-C }\end{array}$ & $8 / 8$ & $8 / 8$ & $8 / 8$ & $8 / 8$ & $8 / 8$ & $7 / 8$ & $7 / 8$ & $7 / 8$ & $8 / 8$ & $8 / 8$ & $8 / 8$ & $8 / 8$ \\
\hline Reversal 1: A-B & $6 / 6$ & $6 / 6$ & $6 / 6$ & $6 / 6$ & $6 / 6$ & $5 / 6$ & $6 / 6$ & $6 / 6$ & $5 / 6$ & $6 / 6$ & $5 / 6$ & $5 / 6$ \\
\hline Reversal 1: B-C & $6 / 6$ & $5 / 6$ & $5 / 6$ & $6 / 6$ & $6 / 6$ & $5 / 6$ & $5 / 6$ & $6 / 6$ & $6 / 6$ & $6 / 6$ & $6 / 6$ & $6 / 6$ \\
\hline $\begin{array}{l}\text { Reversal 1: } \\
\text { Mixed A-B/B-C }\end{array}$ & $7 / 8$ & $8 / 8$ & $8 / 8$ & $8 / 8$ & $8 / 8$ & $7 / 8$ & $7 / 8$ & $7 / 8$ & $8 / 8$ & $8 / 8$ & $8 / 8$ & $8 / 8$ \\
\hline Baseline 2: A-B & $6 / 6$ & $6 / 6$ & $6 / 6$ & $6 / 6$ & $6 / 6$ & $6 / 6$ & $5 / 6$ & $6 / 6$ & $5 / 6$ & $6 / 6$ & $6 / 6$ & $5 / 6$ \\
\hline Baseline 2: B-C & $6 / 6$ & $6 / 6$ & $6 / 6$ & $5 / 6$ & $6 / 6$ & $6 / 6$ & $5 / 6$ & $6 / 6$ & $6 / 6$ & $5 / 6$ & $6 / 6$ & $6 / 6$ \\
\hline $\begin{array}{l}\text { Baseline 2: } \\
\text { Mixed A-B/B-C }\end{array}$ & $8 / 8$ & $8 / 8$ & $8 / 8$ & $8 / 8$ & $8 / 8$ & $8 / 8$ & $8 / 8$ & $8 / 8$ & $7 / 8$ & $7 / 8$ & $8 / 8$ & $8 / 8$ \\
\hline Reversal 2: A-B & $6 / 6$ & $6 / 6$ & $6 / 6$ & $6 / 6$ & $6 / 6$ & $5 / 6$ & $5 / 6$ & $6 / 6$ & $6 / 6$ & $6 / 6$ & $6 / 6$ & $6 / 6$ \\
\hline Reversal 2: B-C & $6 / 6$ & $6 / 6$ & $6 / 6$ & $5 / 6$ & $6 / 6$ & $6 / 6$ & $5 / 6$ & $6 / 6$ & $6 / 6$ & $6 / 6$ & $5 / 6$ & $6 / 6$ \\
\hline $\begin{array}{l}\text { Reversal 2: } \\
\text { Mixed A-B/B-C }\end{array}$ & $8 / 8$ & $8 / 8$ & $8 / 8$ & $8 / 8$ & $8 / 8$ & $8 / 8$ & $8 / 8$ & $8 / 8$ & $8 / 8$ & $7 / 8$ & $8 / 8$ & $8 / 8$ \\
\hline Baseline 3: A-B & $6 / 6$ & $6 / 6$ & $6 / 6$ & $6 / 6$ & $6 / 6$ & $6 / 6$ & $5 / 6$ & $6 / 6$ & $6 / 6$ & $6 / 6$ & $6 / 6$ & $6 / 6$ \\
\hline Baseline 3: B-C & $6 / 6$ & $6 / 6$ & $6 / 6$ & $6 / 6$ & $5 / 6$ & $6 / 6$ & $6 / 6$ & $6 / 6$ & $6 / 6$ & $6 / 6$ & $5 / 6$ & $6 / 6$ \\
\hline $\begin{array}{l}\text { Baseline 3: } \\
\text { Mixed A-B/B-C }\end{array}$ & $8 / 8$ & $8 / 8$ & $8 / 8$ & $8 / 8$ & $8 / 8$ & $8 / 8$ & $7 / 8$ & $8 / 8$ & $8 / 8$ & $8 / 8$ & $8 / 8$ & $8 / 8$ \\
\hline
\end{tabular}




\begin{tabular}{lllllllllllll}
\hline Reversal 3: A-B & $6 / 6$ & $6 / 6$ & $6 / 6$ & $6 / 6$ & $6 / 6$ & $5 / 6$ & $5 / 6$ & $6 / 6$ & $6 / 6$ & $6 / 6$ & $6 / 6$ & $6 / 6$ \\
Reversal 3: B-C & $6 / 6$ & $6 / 6$ & $5 / 6$ & $6 / 6$ & $5 / 6$ & $5 / 6$ & $6 / 6$ & $6 / 6$ & $6 / 6$ & $6 / 6$ & $6 / 6$ & $5 / 6$ \\
Reversal 3: & $8 / 8$ & $8 / 8$ & $7 / 8$ & $8 / 8$ & $8 / 8$ & $7 / 8$ & $7 / 8$ & $8 / 8$ & $8 / 8$ & $8 / 8$ & $8 / 8$ & $8 / 8$ \\
Mixed A-B/B-C & & & & & & & & & & & & \\
\hline
\end{tabular}

\section{Experiment 3}

\begin{tabular}{|c|c|c|c|c|c|c|c|c|c|c|c|c|}
\hline \multirow{5}{*}{$\begin{array}{l}\text { Baseline 1: A-B } \\
\text { Baseline 1: B-C } \\
\text { Baseline 1: } \\
\text { Mixed A-B/B-C }\end{array}$} & \multicolumn{4}{|c|}{ Participant 1} & \multicolumn{4}{|c|}{ Participant 2} & \multicolumn{4}{|c|}{ Participant 3} \\
\hline & $T T 1$ & $T T 2$ & TT3 & TT4 & TT1 & $T T 2$ & TT3 & TT4 & $T T 1$ & $T T 2$ & TT3 & TT4 \\
\hline & $6 / 6$ & $6 / 6$ & $6 / 6$ & $6 / 6$ & $6 / 6$ & $6 / 6$ & $6 / 6$ & $6 / 6$ & $6 / 6$ & $6 / 6$ & $6 / 6$ & $6 / 6$ \\
\hline & $6 / 6$ & $6 / 6$ & $6 / 6$ & $5 / 6$ & $6 / 6$ & $6 / 6$ & $5 / 6$ & $6 / 6$ & $6 / 6$ & $5 / 6$ & $5 / 6$ & $6 / 6$ \\
\hline & $8 / 8$ & $8 / 8$ & $8 / 8$ & $8 / 8$ & $8 / 8$ & $8 / 8$ & $7 / 8$ & $8 / 8$ & $7 / 8$ & $7 / 8$ & $8 / 8$ & $7 / 8$ \\
\hline Reversal 1: A-B & $5 / 6$ & $6 / 6$ & $5 / 6$ & $6 / 6$ & $6 / 6$ & $5 / 6$ & $5 / 6$ & $6 / 6$ & $5 / 6$ & $6 / 6$ & $5 / 6$ & $6 / 6$ \\
\hline Reversal 1: B-C & $6 / 6$ & $5 / 6$ & $6 / 6$ & $6 / 6$ & $5 / 6$ & $6 / 6$ & $6 / 6$ & $5 / 6$ & $5 / 6$ & $5 / 6$ & $5 / 6$ & $6 / 6$ \\
\hline $\begin{array}{l}\text { Reversal 1: } \\
\text { Mixed A-B/B-C }\end{array}$ & $8 / 8$ & $8 / 8$ & $8 / 8$ & $8 / 8$ & $8 / 8$ & $8 / 8$ & $7 / 8$ & $8 / 8$ & $7 / 8$ & $7 / 8$ & $8 / 8$ & $7 / 8$ \\
\hline Baseline 2: A-B & $6 / 6$ & $6 / 6$ & $6 / 6$ & $6 / 6$ & $6 / 6$ & $6 / 6$ & $5 / 6$ & $6 / 6$ & $6 / 6$ & $6 / 6$ & $5 / 6$ & $6 / 6$ \\
\hline Baseline 2: B-C & $6 / 6$ & $5 / 6$ & $6 / 6$ & $6 / 6$ & $6 / 6$ & $6 / 6$ & $6 / 6$ & $6 / 6$ & $6 / 6$ & $6 / 6$ & $6 / 6$ & $6 / 6$ \\
\hline $\begin{array}{l}\text { Baseline 2: } \\
\text { Mixed A-B/B-C }\end{array}$ & $8 / 8$ & $8 / 8$ & $7 / 8$ & $8 / 8$ & $8 / 8$ & $8 / 8$ & $8 / 8$ & $8 / 8$ & $7 / 8$ & $7 / 8$ & $8 / 8$ & $8 / 8$ \\
\hline Reversal 2: A-B & $6 / 6$ & $6 / 6$ & $6 / 6$ & $6 / 6$ & $6 / 6$ & $6 / 6$ & $6 / 6$ & $6 / 6$ & $6 / 6$ & $6 / 6$ & $6 / 6$ & $6 / 6$ \\
\hline Reversal 2: B-C & $6 / 6$ & $6 / 6$ & $5 / 6$ & $6 / 6$ & $6 / 6$ & $5 / 6$ & $6 / 6$ & $6 / 6$ & $6 / 6$ & $6 / 6$ & $6 / 6$ & $6 / 6$ \\
\hline $\begin{array}{l}\text { Reversal 2: } \\
\text { Mixed A-B/B-C }\end{array}$ & $8 / 8$ & $7 / 8$ & $7 / 8$ & $7 / 8$ & $8 / 8$ & $8 / 8$ & $8 / 8$ & $8 / 8$ & $8 / 8$ & $8 / 8$ & $8 / 8$ & $8 / 8$ \\
\hline
\end{tabular}

